\title{
Fuzzy definition of Rural Urban Interface: An application based on land use change scenarios in Portugal
}

\author{
Federico Amato $^{\mathrm{a}, *}$, Marj Tonini ${ }^{\mathrm{b}}$, Beniamino Murgante ${ }^{\mathrm{a}}$, Mikhail Kanevski ${ }^{\mathrm{b}}$ \\ a University of Basilicata, Viale dell'Ateneo Lucano 10, 85100 Potenza, Italy \\ ${ }^{\mathrm{b}}$ Institute of Earth Surface Dynamics, Faculty of Geosciences and Environment, University of Lausanne, Quartier UNIL-Mouline, Bâtiment Géopolis, CH-1015 \\ Lausanne, Switzerland
}

\section{A R T I C L E I N F O}

\section{Article history:}

Received 4 August 2017

Received in revised form 16 March 2018

Accepted 22 March 2018

Available online 31 March 2018

\section{Keywords:}

Rural-urban interface

Land use-land cover changes

Multilayer perceptron

Fuzzy set theory

Uncertainty assessment

\begin{abstract}
A B S T R A C T
Land cover dynamics influence the spatio-temporal evolution of the Rural-Urban Interface (RUI). This represents the most prone area for human-caused forest fires ignitions in Mediterranean countries. Traditionally, RUI mapping is based on the measurement of the distances among specific land covers. This methodology suffers from the definition of pre-established fixed parameters. To avoid this arbitrariness, a new procedure based on Multilayer Perceptron and Fuzzy Set Theory is introduced in this paper. This allows to develop continuous non-categorical maps expressing the possibility of being part of this interface. Thus, an innovative way for assessing the uncertainty in identifying RUI is presented. The proposed methodology has been applied to the case study of Portugal, elaborating a future scenario for the RUI. The results show how the framework proposed in this paper is able to correctly identify the areas belonging to this interface, providing useful information for forest fires -prevention policies.
\end{abstract}

(c) 2018 Elsevier Ltd. All rights reserved.

\section{Introduction}

Wildland-Urban Interface (WUI) was first defined as the area "where humans and their development meet or intermix with wildland fuels" (USDI - US Department Of The Interior and USDA US Department Of Agriculture, 2001). Lately, compounded by climate changes, urban growth and the fragmentation of rural areas, WUI became the central focus of wildland fire policy (Stewart et al., 2007).

Several approaches have been proposed by the scientific community to map the WUI (Bar-Massada et al., 2013; Conedera et al., 2015; Herrero-Corral et al., 2012; Lampin-Maillet et al., 2010; Radeloff et al., 2005). These are prevalently GIS based, where the boundaries of the WUI area are defined through a fixed-distance buffer around buildings and overlapping the wild vegetation/forest. This assumption relies on the observation that human presence, associated to factors such as the population and buildings density or the proximity to roads or single houses, positively affects the probability of forest fires occurrences. Therefore, the spatial

\footnotetext{
* Corresponding author.

E-mail addresses: federico.amato@unibas.it (F. Amato), marj.tonini@unil.ch (M. Tonini), beniamino.murgante@unibas.it (B. Murgante), mikhail.kanevski@unil. ch (M. Kanevski).
}

extent of WUI is determined by anthropogenic variables, wild vegetation and the buffer value.

Such WUI maps are useful support tools for fire managers, but suffer the definition of fixed parameters and a pre-established buffer's width. It was pointed out that maps relying on the same broad definitions and input data can result in hugely different WUI classifications due to differences in the analytical methods used to produce them (Stewart et al., 2009). Moreover, even when similar conceptual models, data sources, parameters and metrics are applied, details of the implementation can lead to different estimates of the WUI's extent (Platt, 2010). Nevertheless, all these methods are appropriate and necessary to give precise indication for fire protection and prevention, provided that their limitations are made explicit, as well as the purpose for which such maps were developed, the quality of the data and the method of analysis.

WUI is not a static concept; to the contrary, it dynamically changes in space and in time, driven by different anthropogenic and environmental factors. For instance, the abandonment of remote rural areas and the consequent urbanization processes favours the expansion of the WUI and enhances the probability that forest fires reach houses and infrastructures (Theobald and Romme, 2007; Viedma et al., 2015; Zhang et al., 2008). Deforestation and afforestation are other factors affecting the WUI dynamics.

Land use and land cover changes (LULCC) are closely related to 
the delimitation of an interface area between urban and rural/ wildland surfaces, where human-caused forest fires are more likely to occur, and represent a main hazard for people, houses and infrastructures. In the last few decades LULCC in European Mediterranean countries have been marked by the progressive abandonment of rural areas under the pressure of urbanization and the expansion of costal tourist centers (Alados et al., 2004). As a consequence, rural activities, such as low-intensity agriculture and grazing practices, were progressively discarded leading to the intensification of forest covers and scrubland vegetation, especially in remote and poor accessible areas (Antrop, 2004; Millington et al., 2007; Poyatos et al., 2003). Urbanization is a very complex and dynamic process that involves natural and the rural lands: these are progressively converted into urban and industrial areas, driven by physical conditions (e.g. topography) and the accessibility to the area (e.g. road network) (Antrop, 2000; Kim et al., 2017). Specifically in Portugal, that in terms of burned area and number of forest fires is among the first three countries in Europe (Moreira et al., 2001; Nunes et al., 2005; Oliveira et al., 2017), the abandonment of rural lands in marginal areas and the coastal urbanization characterized the landscapes changes since 1980 (Diogo and Koomen, 2012; Nunes et al., 2016; Van Doorn and Bakker, 2007).

In this context, the notion of WUI has to be redefined, taking into account the related rural-urban process and the changes of the landscape. Therefore, the broader concept of Rural-Urban Interface (RUI) is more appropriate. RUI has been identified by recent studies as the most fire prone area in Mediterranean countries (BadiaPerpinyá and Pallares-Barbera, 2006; Catry et al., 2009; Moreira et al., 2009). LULCC and RUI have a strong mutual influence: on the one hand, each vegetated land cover type has a specific fire proneness (Pereira et al., 2014; Oliveira et al., 2014); on the other hand, fire affects the landscape pattern and dynamics by changing the vegetation structure and soil processes (Pausas et al., 2008; Viedma, 2008). This suggests the opportunity of investigating the spatio-temporal changes of the RUI and make prevision about its future evolution by analysing and modelling LULCC.

Land use science is an extremely investigated field (Foley et al., 2005; Kalnay and Cai, 2003; Ramankutty and Coomes, 2016). In the last decades, particular attention was paid to LULCC and broad ranges of models have been developed for research and management purposes. These include tools to analyse and quantify changes incurred between two or more periods and can incorporate sophisticated models to predict land use/land cover future scenarios (Martellozzo et al., 2018). Several of these last LULCC models have been designed to facilitate decision-making processes in the field of landscape protection, natural hazards and disaster risk management, urban growth regulation (Foley et al., 2011; Amato et al., 2015, 2016; Muñoz-Rojas et al., 2015; Di Palma et al., 2016; Nunes de Oliveira et al., 2017; Young, 2017). Routines and software developed to predict LULCC and future scenario implement models that can broadly be classified as based on deductive or inductive approaches (Overmars et al., 2007a, 2007b). The latter are based on past land use/land cover (LULC) in a raster format (i.e. pixel units) to estimate the change transition potential, and apply mathematical/ statistical functions including explanatory spatial variables to predict future scenarios. Inductive models are commonly used in land change science, in which emphasis is placed on fitting parameters to observations. In contrast, deductive approaches (including agent-based models) simulate the interactions among a set of socalled agents (e.g. land use, householders, farmers, etc.) to analyse their effects on the system as a whole, attaining deeper knowledge of the process. These models, focusing on actors' behaviours, are more popular among economists and decision makers (d'Aquino et al., 2002; Parker et al., 2003; Robinson et al., 2007).

This paper proposes an innovative approach to define the RUI avoiding the definition of rigid boundaries and eliminating their dependence on predefined parameters, such as the buffer width around the concerned land cover classes. A spatio-temporal analysis of RUI has been performed here, based on LULCC model, which allowed to define future scenario maps. These represent a useful support tool for the development of effective fire prevention policies. The methodology has been applied to the case study of Portugal (Western Europe), an area particularly affected by fires.

\section{Materials and methods}

In this study we introduce a spatially explicit inductive approach to analyse spatio-temporal changes of the RUI and to simulate future scenarios based on the evolution and prediction of the RUI in Portugal from 1990 up to 2030. Among the existing implemented approaches, we selected the Land Change Modeler (LCM ${ }^{\mathrm{TM}}$, also available as an $\operatorname{ArcGIS}^{\circledR}$ extension); it includes a supervised neural network model, namely Multilayer Perceptron (MLP) trained by backpropagation, to produce probability maps allowing to elaborate future scenarios. This approach fits well when the process under study is non-linear, as it is the case for simulating urban growth and rural development. Moreover, compared with other models/software, LCM provides an higher accuracy of simulations when using MLP (Eastman et al., 2005).

\subsection{Study area}

Portugal is located in the south-western Europe. It covers the western coast of the Iberian Peninsula for about $200 \mathrm{~km}$ (Fig. 1). Mainland has surface of $89,000 \mathrm{~km}^{2}$ with an altitude range from sea level to about $2000 \mathrm{~m}$ in the north central region. Continental Portugal has a temperate climate characterized by wet and mild winters and dry summers, warm in the northern area and hot in the southern. This typical Mediterranean type of climate suffers from the influence of the Atlantic Ocean that bathes its western and southern coasts (Instituto Português do Mar e da Atmosfera, 2018). The country is split by the Tagus River in two parts of approximately the same size, but characterized by a different topography and subclimatic conditions. In the northern area prevails a mountainous landscape interspaced with river valleys, with an annual average temperature ranging from $8{ }^{\circ} \mathrm{C}$ to $12^{\circ} \mathrm{C}$. The southern part is characterized by rolling plains with an average annual temperature of about $17{ }^{\circ} \mathrm{C}$. Vegetation grows in the spring season, while it experiences hydric and thermical stress during the summer months, when most fire occurrences are reported. In agreement with the climate and the local topography, forests are predominant in the northern half of the country, while in the southern area prevail agricultural lands and scrub types of vegetation in the south coast(EEA, 1994) Urban areas are mostly located in the northwestern part of the country; here there are the two metropolitan areas of Porto and Lisbon. In the southern part only the Algarve coastal region, which has its administrative centre in the city of Faro, is densely populated.

Fire events in Portugal display a regime strongly related to climate and weather conditions, resulting in about $90 \%$ of burned areas concentrated in the summer season (June to September). Many studies report that in the Iberian Peninsula, weather and climate are responsible for about two-thirds of variability of the total annual burned area (Pereira et al., 2013, 2005; Trigo et al., 2016). As regards to the distribution in space and in time of forest fires and burned area in the last decades, the northern Portuguese area is much more affected than the southern: namely, in the period 1990-2013, 25,322 fires were registered in the first, compared with 1951 in the second (considering only burned areas > 5 ha) (Tonini et al., 2017b). Density maps derived from this 


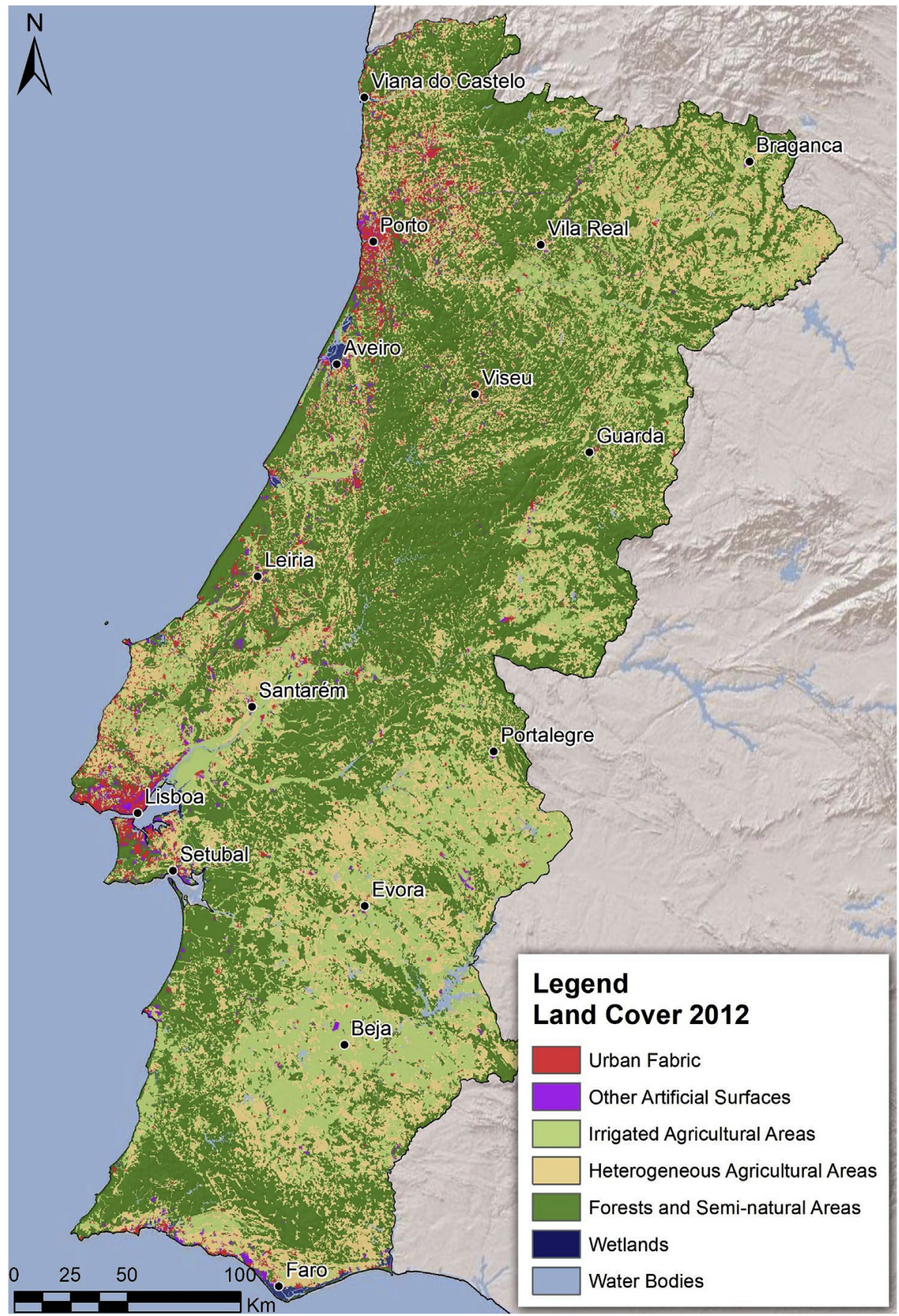

Fig. 1. Land cover classsification based on the second level of the CORINE Land Cover (CLC) 2012 inventory.

same dataset revealed the presence of hot spots almost each year in the northern region, with a higher concentration in the northeastern more populated areas.

\subsection{Data acquisition and pre-processing}

To perform the simulation, three land cover maps were used as inputs. These were collected from the CORINE Land Cover (CLC) inventory (Copernicus Programme, http://land.copernicus.eu). CLC maps have been produced for the years 1990, 2000, 2006, 2012. However, the 2006 map has not been considered in this work, in order to have more homogeneous time-step between the time- periods. CLC has a minimum mapping unit (MMU) of 25 ha for areal phenomena, and a minimum width of $100 \mathrm{~m}$ for the linear ones. Land covers are classified into 44 classes articulated over three levels. For the present purpose, CLC maps have been reclassified with reference to the second level as reported in Table 1.

From a parallel research study focused on the assessment of RUI and related land covers in Portugal (Tonini et al., 2017a), it resulted that forest and semi-natural areas, jointly with heterogeneous agricultural areas, constitute in this country the vegetated burnable area. Therefore, the RUI's boundaries, needed to validate the model, were defined by spatially intersecting these classes with areas surrounding artificial surfaces. The buffer's width was fixed at $1 \mathrm{~km}$, 
Table 1

Land cover classsification based on the second level of the CORINE Land Cover (CLC) nomenclature.

\begin{tabular}{ll}
\hline Proposed Classification & CLC Nomenclature (Level 2) \\
\hline Urban fabric & Urban fabric \\
Other artificial surfaces & Industrial, commercial and transport units \\
& Mine, dump and construction sites \\
& Artificial, non-agricultural vegetated areas \\
Irrigated agricultural areas & Arable land \\
& Permanent crops \\
Heterogeneous agricultural areas & Pastures \\
Forest and semi-natural areas & Heterogeneous agricultural areas \\
& Forest \\
Wetlands & Shrub and/or herbaceous vegetation associations \\
Water bodies & Open spaces with little or no vegetation \\
& Inland wetlands \\
& Coastal wetlands \\
& Inland waters \\
\hline
\end{tabular}

which is consistent with worldwide-applied values (i.e. $1.5 \mathrm{mi}$ $(\sim 2.4 \mathrm{~km}$ ) in USA (Radeloff et al., 2005) and from $100 \mathrm{~m}$ to $400 \mathrm{~m}$ around single settlements in Europe (Bouillon et al., 2012).

In calibrating the MLP neural network, a number of driving variables have been selected and used as nodes in the input layer. Digital Elevation Model, slope and aspect (i.e. the downslope direction of the maximum rate of change in value from each cell to its neighbours measured clockwise in degrees) were downloaded from the Copernicus database of the European Environment Agency (Reference Data - Copernicus Land Monitoring Service website). Agricultural and population census data have been derived from the Portuguese National Institute of Statistics (Portal do Instituto Nacional de Estatística, n.d.). Distance from primary roads and from the cities with more than 50.000 inhabitants resulted from the Open Street Map Database (OpenStreetMap website). Soil thickness, ph, texture and ecological value have been derived from EPIC WebGIS (EPIC WebGIS Portugal, n.d.), an interactive spatial data infrastructure, which provides georeferenced cartography at national scale.

Other variables were derived from a change detection analysis between the inputs of CLC maps. Hence, an Evidence Likelihood function was used to evaluate the relationship among the experienced changes, the Protected Areas and the European protected sites belonging to the Natura 2000 network (derived from the Portuguese Law, 2008/142), the European statistical administrative units NUTS (Nomenclature des unités territoriales statistiques) of second and third level and the changes themselves. Finally, the distance from each land cover class has been considered as a dynamic variable, i.e. a variable that changes over time, depending on the intermediate stages of the simulation.

All data have been produced in raster format with a spatial resolution of $100 \mathrm{~m} \times 100 \mathrm{~m}$. They have then been projected in the ETRS89/ETRS-LAEA spatial reference system (EPSG: 3035). This is generally used for statistical mapping at all scales as it ensures a true area representation.

\subsection{Forecasting the rural urban interface: model setting}

In this paper, the use of a LULCC model is proposed to analyse and simulate the variation of RUI in time. The extent of the RUI is strictly dependent on land cover, as it represents the interface between urban and burnable vegetated rural areas. Changes in artificial surfaces, forests and non-irrigated/heterogeneous agricultural areas affect the extensions of the RUI, indeed. Therefore, a proxy to predict RUI for future scenarios is the simulation of changes in LULC and, consequently, the definition of new boundaries for the prospective RUI.
The main LULCC prediction models are based on an a priori knowledge of the study area and on the driving forces that explain changes in land use (Batty, 1997). This information is used as spatially explicit variable to calibrate the models. However, the definition of the rules to characterize the likelihood that a transition between two different land cover classes will occur is an open issue. To solve it, several transition potential models have been proposed in the literature (Eastman et al., 2005; Saeidi et al., 2017; van Vliet et al., 2016). In the present study, as highlighted before, the MLP neural network algorithm was used for the transition potential modelling. Subsequently, a Markov Chain (MC) application allowed the definition of the change demand, i.e. the quantity of changes expected among each pairwise combination of land cover classes in a certain time. Finally, a threshold procedure was used for the change allocation modelling, allowing ranking the pixels of the transition potential map starting from the assumption that the pixels experiencing a change in a specific iteration of the simulation process are those with a higher transition potential.

To correctly calibrate and validate the model, at least three land cover maps, corresponding to three different periods (i.e. $T_{0}, T_{1}$ and $T_{2}$ ) are needed. The model is then performed using the $T_{0}$ and $T_{1}$ land cover maps as input to generate a simulation at the time $T_{2}$. Therefore, the obtained map is compared with the real land cover map at the time $T_{2}$ and Kappa statistics are evaluated (Pontius, 2000). If the validation procedure confirms a good quality of the simulation, the same hyper-parameters used in this stage to calibrate the MLP are used to model $T_{3}$ by means of the $T_{1}$ and $T_{2}$ land cover input maps as input. To focus the evaluation of the calibration procedure on the validation of the MLP application and, therefore, on the quality of the transition potential maps, in the calibration stage the Markovian definition of the change demand has not been applied. Whereas, the real transition matrix measured between the $T_{1}$ and $T_{2}$ land cover maps has been used, while MC model was applied to quantify the transition between different land covers in the period $T_{2}-T_{3}$.

This technique gave as output a land use simulation map for $T_{3}$. Subsequently, the RUI could be identified by applying buffers to the land cover classes whose interaction defines this specific interface. However, the RUI obtained with this procedure is intensely dependent on the selection by the user of an appropriate buffer distance. Moreover, a binary logic to define the membership of a space unit to the RUI seems inappropriate. This is even truer when the RUI definition is based on the results of a previous simulation. In that case, a dichotomous identification of RUI would assume that the modelled land cover is precise, exhaustive and unambiguous (Zadeh, 1973a; Zimmermann, 2010a). Nevertheless, even a wellstructured and well-calibrated LULCC model is unlikely to ensure 
a perfect recognition of all the structure and the patterns of the real world.

To overcome to this issue, in this study we applied fuzzy sets theory as a method to deal with uncertainty and vagueness in the definition of the boundaries of the RUI (Asadi et al., 2017; Uusitalo et al., 2015). This approach overcomes the traditional Boolean classification of spatial units, in which a cell is either belonging to RUI or not. Rather, it expresses the possibility of a pixel of belonging to the RUI set.

To model this "possibility" map, the Transition Potential Model based on MLP have been used to generate two transition probability maps for the time $T_{2}$. The first expresses the probability of having a transition from any land cover class to the urban area, while the second expresses the probability of having a transition from any land cover class to the rural surfaces. In agreement with our previous finding (Tonini et al., 2017a), CLC classes considered to define these transition maps are the following: "urban fabric" for urban area and "forest and semi-natural areas" together with "heterogeneous agricultural areas" for the rural surfaces.

The fuzzification of these two maps allowed their overlapping, giving as an output a map expressing the possibility of each cell to belong to RUI. For the tuning of the fuzzification parameters, and for the validation of the possibility map, a dataset containing points belonging to the RUI for $T_{2}$ was employed. This RUI map has been defined through the commonly-used procedure based on fixed distance buffers. Specifically, a $1 \mathrm{~km}$ buffer has been measured around both the urban area (i.e. "urban fabric"). Hence, the areas belonging to RUI were defined as the one belonging to the intersection of this areas with the burnable vegetated rural area (i.e. "Forest and semi-natural areas" and "Heterogeneous agricultural areas") (Tonini et al., 2017a). Specifically, the procedure was evaluated by the estimation of the Receiver Operating Characteristic (ROC) and the associated Area Under the Curve (AUC) (Hanley and McNeil, 1982; Robin et al., 2011). Once the validation confirmed the quality of the fuzzification process, the same parameters were used to create a possibility map for $T_{3}$.

Fig. 2 shows the general flowchart of the methodology proposed in this paper for the calibration, validation and simulation steps.

\subsubsection{Calibration of multilayer perceptron (MLP)}

The main purpose of this phase is to define proper parameters to be used to minimise the error generated through the application of the MLP. The model performances were evaluated by measuring the root mean square error (RMSE), indeed. MLP architecture is constituted by a series of processing units, named neurons after the metaphor of the biological neuroscience, able to compute and model a specific problem. MLP are extremely useful when phenomena are characterized by a strong nonlinearity or when the analysis is carried out into a high dimensional space (i.e. independent variables driving the process) (Haykin, 2008).

When used for the creation of transition potential maps, the areas that experienced a land cover change are used as training samples to analyse the relationship between input and output ( $\mathrm{Li}$ and Yeh, 2002, 2001). The input layer is constituted by the driving variables. These are commonly considered as good explanatory variables to be used as inputs in different models (Silva et al., 2016; van Vliet et al., 2012). According to Meyfroidt (2016), driving forces in LULCC are those factors that are cause of land or environmental change and that have a marked association with the nature of the change. Besides, the output layer is defined by all the possible transitions among the different land cover classes included in the model. It also includes the possibility of having a persistence of the considered classes. As soon as the training is completed, new data are presented to the network and the activation levels are defined for all the modelled classes. As a result, the transition potential maps are generated. In our case, these represent the probability of each pixel of having a change from its starting land cover to urban cover and forests or heterogeneous agricultural areas, respectively. These maps were than used in the fuzzification process.

\subsubsection{Validation}

Validation is a crucial phase to estimate the performaces of the calibrated model. Specific procedures were implemented to assess the quality of both the LULC prediction, both the fuzzy possibility map of RUI.

The accuracy of the LULCC prediction was carried out through the measurement of Kappa coefficient of agreement (Pontius, 2000). Naming $s$ the generic element of the simulation map $S$ and $a$ the generic element of the reference land cover map $A$, and assuming to have $i=1,2, . . c$ possible land cover classes, the evaluation of the correspondence between the two maps is given considering the observed fraction of agreement $P_{0}$, the expected fraction of agreement $P_{e}$, and the maximum fraction of agreement $P_{\max }$ (Van Vliet et al., 2011). These values are defined as

$P_{o}=\sum_{i=1}^{c}[p(a=i \hat{s}=1]$

$P_{e}=\sum_{i=1}^{c}[p(a=i) \cdot p(s=1)]$

$P_{\max }=\sum_{i=1}^{c}[\min p(a=i), p(s=i)]$

where $p(a=i)$ is the fraction of cells having the land cover $i$ in the map $A$ and $p(s=i)$ indicates the number of cells having the land cover $i$ in $S$. Kappa is then derived from these values through the equation

Kappa $=\frac{P_{o}-P_{e}}{1-P_{e}}$

However, it is also possible to consider Kappa as the product of two other measures, the Kappa $a_{\text {Location }}$ and the Kappa $a_{\text {Histogram }}$. The mathematical formulation of the two is given by

Kappa $_{\text {Location }}=\frac{P_{o}-P_{e}}{P_{\max }-P_{e}}$

Kappa $_{\text {Histogram }}=\frac{P_{\text {max }}-P_{e}}{1-P_{e}}$

While the former quantifies the spatial position agreement between the categorical values of the two maps, the latter measures the quantitative agreement among their class sizes (Amato et al., 2017).

Fuzzy set theory was applied to generate a map describing the possibility of each pixel to belong to the RUI. Fuzzy sets are an extension of the conventional crisp (i.e. Boolean) sets. The latter are defined as sets in which each member matches the class concept and the class boundaries are sharp. A membership function for a crisp set can have either value 0 or 1 , meaning that the generic observation $z$ can either be or not be a part of the set (Zadeh, 1965). However, in fuzzy sets theory crisps sets are considered as a case of partial membership, while the general theory is applied to describe those situations in which the class boundaries cannot be precisely defined (Sheehan and Gough, 2016; Wieland and Mirschel, 2017; Zadeh, 2008, 1973b). 


\section{Calibration}

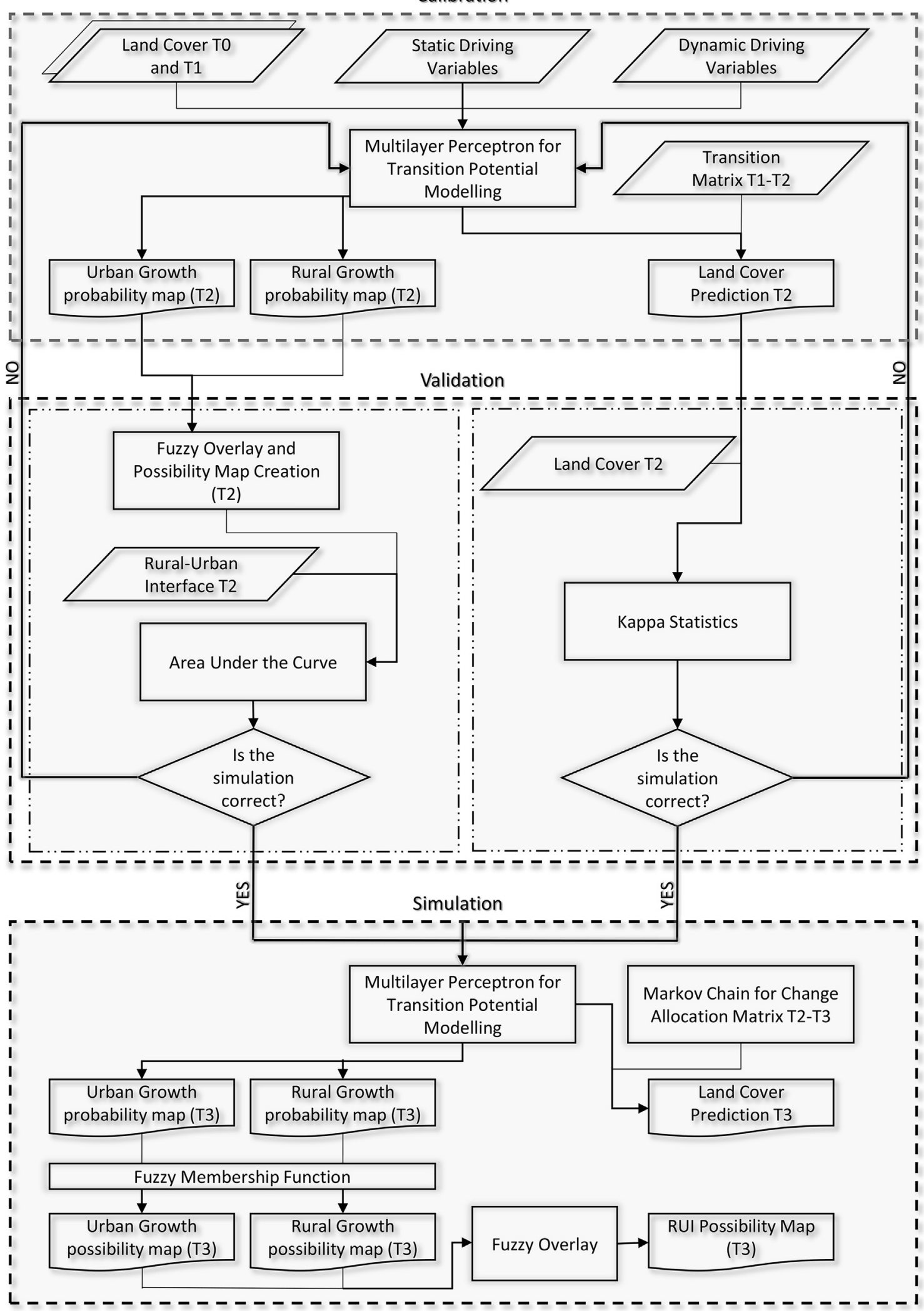

Fig. 2. Flowchart of calibration, validation and simulation procedures. 
Given the space of objects $Z$, the fuzzy set $A$ in $Z$ is

$A=\left(z, M F_{A}^{Z}(z)\right) \quad$ for all $z \in Z$

In which $M F_{A}^{Z}(z)$ is the membership function of $z$ in $A$. It is crucial to comprehend how the membership function reflects a degree of belonging to a set based not on probability, but on possibility (Bai and Wang, 2006). Hence, $M F_{A}^{Z}(z)$ expresses the grade of compatibility of the predicate related to $A$ and $z$ with a scale that can vary continuously in the range $(\mathbf{0 , 1})$ (Luo and Dimitrakopoulos, 2003). Authors have proposed different kinds of fuzzy membership functions (Wang and Mendel, 1992; Zimmermann, 2010b, 2001). In this work, the fuzzy near membership function and the fuzzy large membership function were implemented (Fig. 3).

Generally speaking, the near membership function is used to calculate fuzziness near to a defined intermediate value. A maximum membership value is assigned to this midpoint, while the other values decrease to 0 depending on a spread parameter. The mathematical formulation for the near membership is:

$M F_{A}^{Z}(z)_{N e a r}=\frac{1}{1+f_{1} *\left(z-f_{2}\right)^{2}}$

Differently, the large membership function is used to stress the tendency of high value of the object $Z$ to have high membership in the fuzzy set. This relationship is expressed by the equation:

$M F_{A}^{Z}(z)_{\text {Large }}=\frac{1}{1+\left(\frac{x}{f_{2}}\right)^{-f_{1}}}$

In both the fuzzy near and the fuzzy large membership functions, $f_{1}$ is the spread and $f_{2}$ is the defined intermediate value.

Given a number of fuzzy sets, the literature proposes several methods to use logical queries to select and combine them (An et al., 1991; Bonham-Carter and Bonham-Carter, 1994). The application of these overlay rules, which are based on a generalization of the conventional operation used in the Boolean sets, imply the computation of a new $M F$ value, which is called joint membership function value (JMF) (Burrough, 1989; Murgante and Las Casas, 2004). To our purposes, we will only present three JMF: the fuzzy Or, the fuzzy Sum and the fuzzy Gamma.

The fuzzy Or operator recalls the Boolean Or logical union, as the $J M F$ is dependent on the maximum value of any of the input set maps. Therefore, it is expressed as:

$J M F_{O R}=\operatorname{MAX}\left(M F_{A}^{Z}(z)\right)_{i}$

Differently, the fuzzy Sum operator is matching with an algebraic product. The mathematical formulation of this operator is:

$J M F_{S U M}=1-\prod_{i=1}^{n}\left(1-\left(M F_{A}^{Z}(z)\right)_{i}\right)$

Through this operator, the output is always larger than, or equal to, the largest contributing fuzzy membership value. This is an increasing function, used when the combination of multiple evidence is considered to be more important that any single membership function used as input.

Finally, the Gamma operator is defined as:

$$
J M F_{\text {GAMMA }}=\left(1-\prod_{i=1}^{n}\left(1-\left(M F_{A}^{Z}(z)\right)_{i}\right)\right)^{\gamma} *\left(\prod_{i=1}^{n}\left(M F_{A}^{Z}(z)\right)_{i}\right)^{\gamma}
$$

where $\gamma$ is defined in the range $(0,1)$. It is possible to demonstrate that the $J M F_{G A M M A}$ includes most of the common JMF operators, including the $J M F_{O R}$, corresponding to a $\gamma$ equal to 0.75 , and the $J M F_{S U M}$, corresponding to a $\gamma$ equal to 1 (Raines et al., 2010).

In this paper, the transition potential maps expressing the probability of having a change toward urban or rural coverages are fuzzified by means of the MF large and near function. This process of fuzzification of probability data has been already investigated (Buckley, 2004; Eslami and Buckley, 2004; Pota et al., 2013; Zadeh, 1999) and applied in geography for the creation of susceptibility maps (Hattab et al., 2013). Subsequently, JMF were evaluated for Or, Sum and Gamma operators. In this paper, a gamma of 0.875 was chosen as an intermediate value between the Sum and Or function. The validation of the obtained possibility maps for RUI was done via the relative operating characteristic (ROC). ROC is a quantitative measure that enables the comparison between a suitability map, which in our case represents the possibility of having RUI, and a binary variable representing the presence or the absence of the considered phenomena. To perform it, the suitability map was divided into a number of percentile groups. For each group, a twoby-two contingency table, whose entries are the hits, the misses, the false alarms and the correct rejections, was defined. The ROC metrics was evaluated by the AUC, which was computed as:

$A U C=\sum_{i=1}^{n}\left[X_{i+t}-X_{t}\right]\left[Y_{i}+Y_{i+1}-Y_{i} / 2\right]$

where, for the percentile threshold $t$ and for $n$ suitability group, $X_{t}$ is the rate of false positive and $Y_{i}$ the rate of true positive, evaluated as:

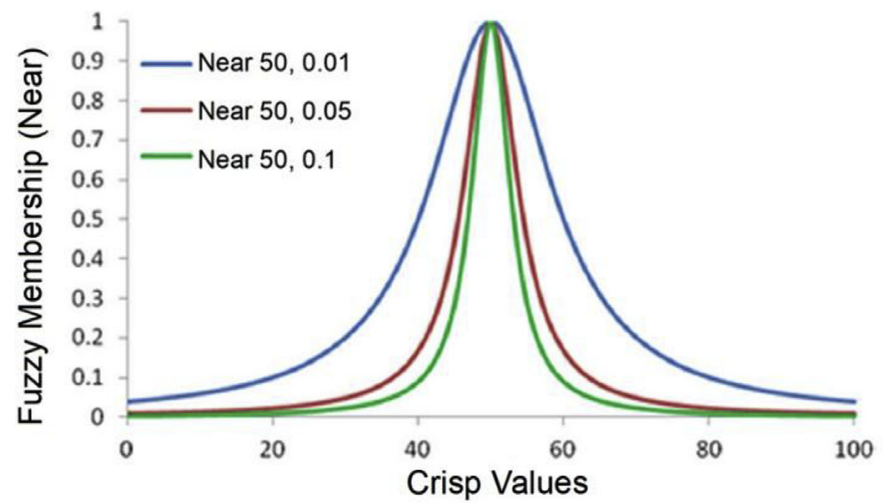

Fig. 3. Fuzzy Large and Fuzzy Near Membership functions drawed using $f_{1}$ equal to 50 and multiple values of. $f_{2}$ 
Table 2

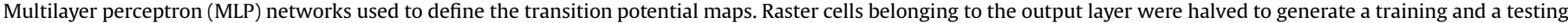
set. RMSE was then measured for both the sets.

\begin{tabular}{|c|c|c|c|c|}
\hline Model/transition to & MLP network structure & Training RMSE & Testing RMSE & Skill Measure \\
\hline Urban fabric & $9-7-6$ & 0.0813 & 0.0824 & 0.9732 \\
\hline Other artificial surfaces & $9-8-6$ & 0.2150 & 0.2198 & 0.7631 \\
\hline Irrigated agricultural areas & $9-6-4$ & 0.0833 & 0.0866 & 0.9913 \\
\hline Heterogeneous agricultural areas & $11-7-4$ & 0.1786 & 0.1812 & 0.9156 \\
\hline Forest and seminatural areas & $9-7-4$ & 0.1487 & 0.1514 & 0.9584 \\
\hline
\end{tabular}

$X_{i}=\frac{F_{t}}{Q} ; \quad Y_{i}=\frac{H_{t}}{P}$

in which $P$ is the number of observations in the binary variable referenced as positives; $Q$ is the number of observations referenced as negative; $F_{t}$ are the fals alarms and $H_{t}$ are the hits (Gil Pontius and Schneider, 2001). A perfect matching among the suitability map and the reference variable corresponds to an AUC of 1 , while a 0.5 value corresponds to a random location of the values of the suitability map. Moreover, in this work both ROC and TOC (Total Operating Characteristic) were computed, as suggested by Pontius and Kangping (2014). TOC allows an easier evaluation of the size of all the entries of the two-by-two contingency table. Differently, ROC only shows the rate of true-positives on the vertical axis versus the rate of false-positives on the horizontal axis for each threshold (Pontius and Parmentier, 2014).

\subsubsection{Simulations}

The parameters obtained through the calibration procedures have been used to predict future transition potential maps (known as "soft prediction") and a potential LULC map for $T_{3}$ (known as "hard prediction"). The difference between "soft" and "hard" prediction is that the first yields the entire set of simulated transitions, while the second yields only one specific transition, selected through a multi-objective land competition model. Hence, to generate a hard prediction, the change demand (i.e. the expected quantities of changes for each land cover class) have to be modelled using MC.

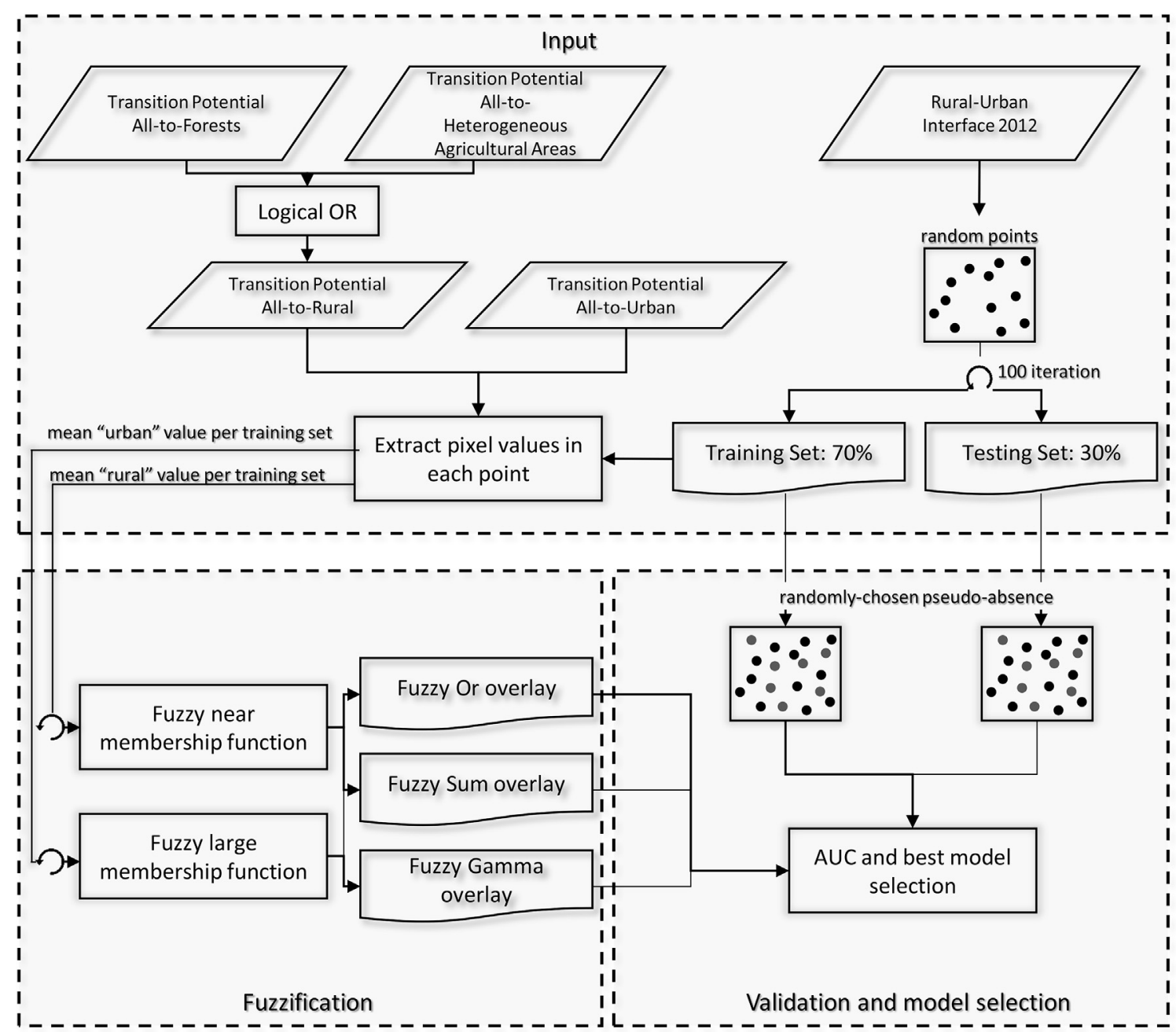

Fig. 4. Flowchart of fuzzification and sensitivity analysis processes. 
MC models are based on the idea that the next step in a process depends only on the current state of the system, independently from the state measured at every previous step (Yang et al., 2012; Pontius and Cheuk, 2006; Mas et al., 2014; Pontius et al., 2008; Guan, 2008). A classical MC approach has been used (Kityuttachai et al., 2013) to predict the transition area matrix to support LULCC prediction. Hence, given the $n$ states of the MC and called $p_{i j}$ the probability measured from the cross tabulation of having a transition from the land cover $j$ to the land cover $i$, then

$A=\left[p_{i j}\right]$

is the transition matrix of the MC and

$X_{n+1}=A X_{n}$

where $X_{n+1}$ and $X_{n}$ are two consecutive state vectors in which the $i_{\text {th }}$ component represents the probability that the system is in the $i_{\text {th }}$ state at that time.

In this study, a quadratic regression is used to interpolate transition probability matrix and model change demand for the LULCC simulation. The basic assumption is that if the frame-period $T_{2}-T_{3}$ separating the prediction time $T_{3}$ and the previous period $T_{2}$ is an even multiple of the frame period $T_{1}-T_{2}$ on which the transition matrix is computed, then the new transition probability matrix is derived by simply powering the starting matrix by a number given by $\left(T_{2}-T_{3}\right) /\left(T_{1}-T_{2}\right)$. Only if the prediction period is between even multiples of the training period, the power rule is used to generate three transition matrixes to cover the prediction period through the resolution of a simple quadratic regression (Takada et al., 2010).

Once modelled the change demand, the obtained transition matrix was used to allocate changes in the future land use map based on the transition potential output of the MLP. The output of this procedure is a land use map for $T_{3}$ on which it was possible to define multiple buffers on the urban and rural classes in order to have an evaluation of the location of the RUI through the traditional procedure. At the same time, a gamma fuzzification of the transition potential maps allowed the definition of a map expressing the possibility of belonging to RUI for $T_{3}$; this represents the main result of the analysis conducted in this paper.

\section{Model calibration and results}

\subsection{Calibration of multilayer perceptron (MLP)}

The MLP network was used to define transition potential maps. As the output layer of MLP is defined by all the possible transitions among the land cover classes, a change detection between the year 1990 and 2000 was performed. A threshold was applied to ignore the transitions affecting a total area smaller than 2500 square kilometres in the entire study area. Thus, transitions from and toward water bodies and wetlands were excluded, as they are mainly due to misclassifications in the CLC maps. The remaining transitions were divided into five groups, depending on the final coverage of the land cover shift. Each group was then used as an output layer in a different MLP neural network. It is important to highlight that the output neurons in this layer are represented both by the possible transitions detected through the change detection, and by the possibility of having a persistence of the initial land cover class.

The input layer included up to 17 driving variables selected among the ones presented in the Materials and Methods section. Each network was first trained with all the variables of interest. Subsequently, a backwards elimination stepwise analysis has been performed to reduce the complexity of the model (Derksen and Keselman, 1992; Holland and Goldberg, 1989). Hence, the least significant variables were dropped one after another and the model was refitted until only statistically significant variables remained in

\section{Boxplot of mean AUC for different Joint Membership Functions}

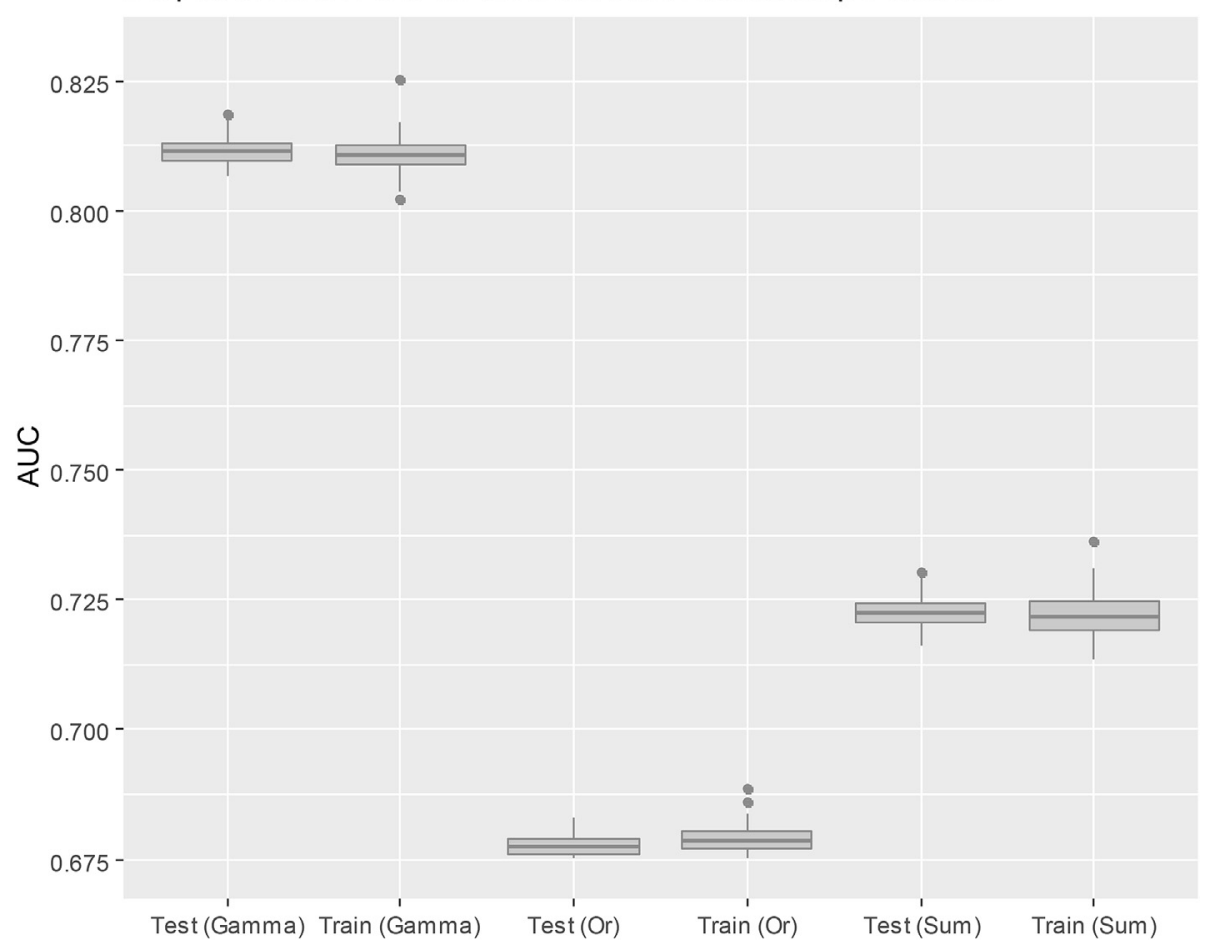

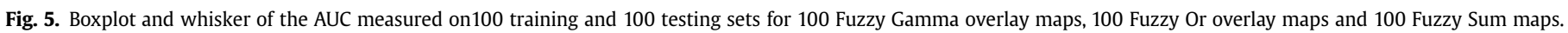




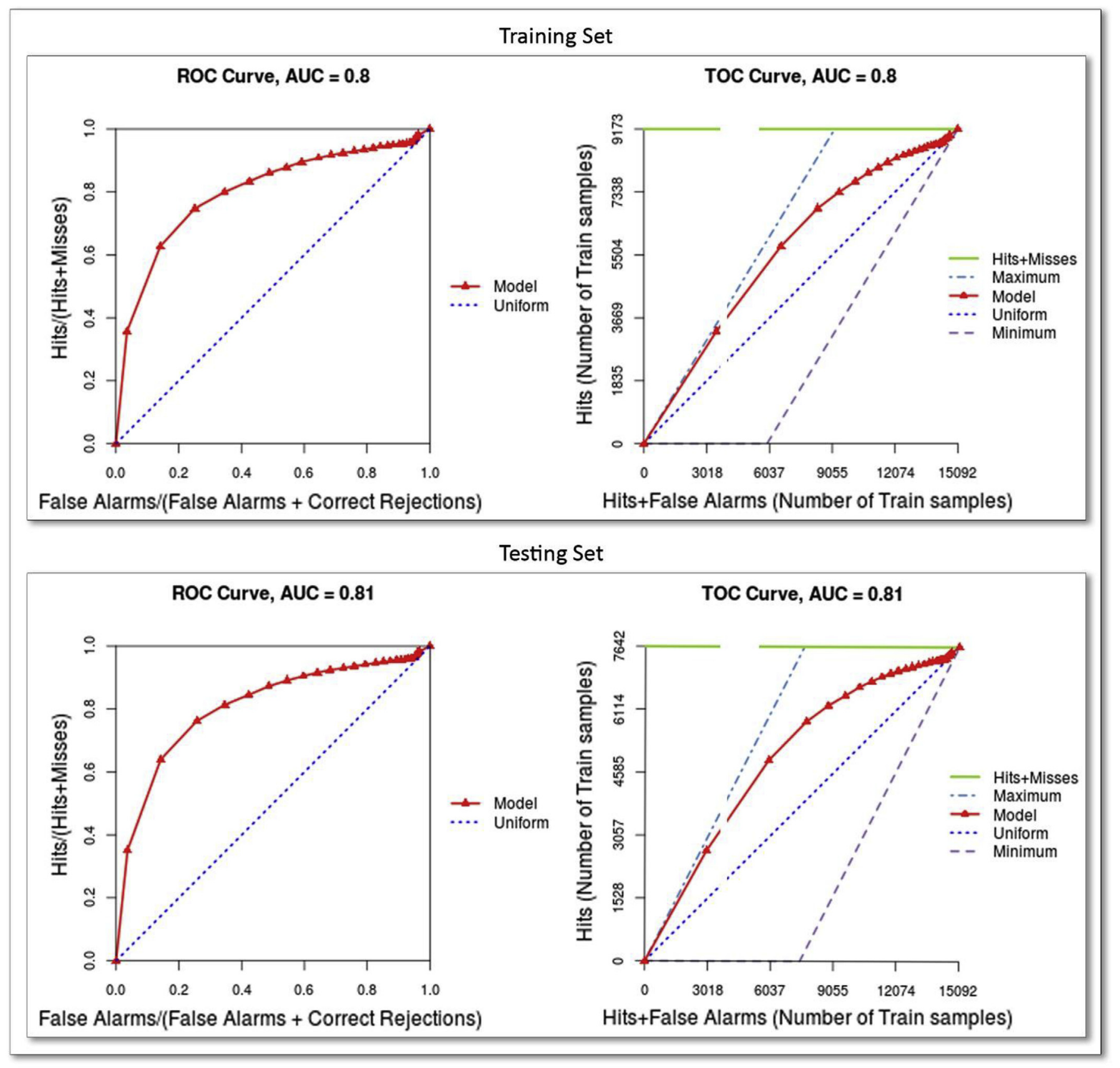

Fig. 6. Best ROC and TOC curves for the Fuzzy Gamma Overlay of both training and testing set.

the network. This methodology allows a reduction of the complexity of the network and an increase in its performances. Table 2 reports the main features of the MLP networks used to calibrate the model. Five networks were implemented based on the final class in the transition process. All the networks were set up using momentum factor equal to 0.5 and sigmoid constant 1 . The skill measure represents the measured accuracy of the transition prediction minus the accuracy expected by chance.

\subsection{Land change model validation}

The transition potential maps obtained with the MLP were used to simulate LULCC up to 2012. The aim of this procedure was to validate the capacity of the MLP to correctly predicting the location of land cover changes. Hence, in this stage the real transition matrix measured on the CLC data for the period 2000-2012 was used to model change demand.

The result was a land cover simulation for the year 2012. A comparison with the reference map for the same year resulted into an overall Kappa is 0.8227 . This value expresses a high capacity of the model to simulate the real-occurred land cover transition. The $K a p p a_{\text {Histogram }}$ has a value of 0.9835 . This very high value is not surprising at all, as it measures the quantity of changes that, in this stage of the model, was defined through the real transition matrix

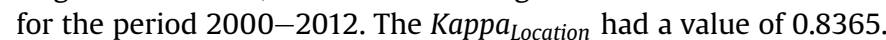
Though this is a good value, it is important to highlight that the 


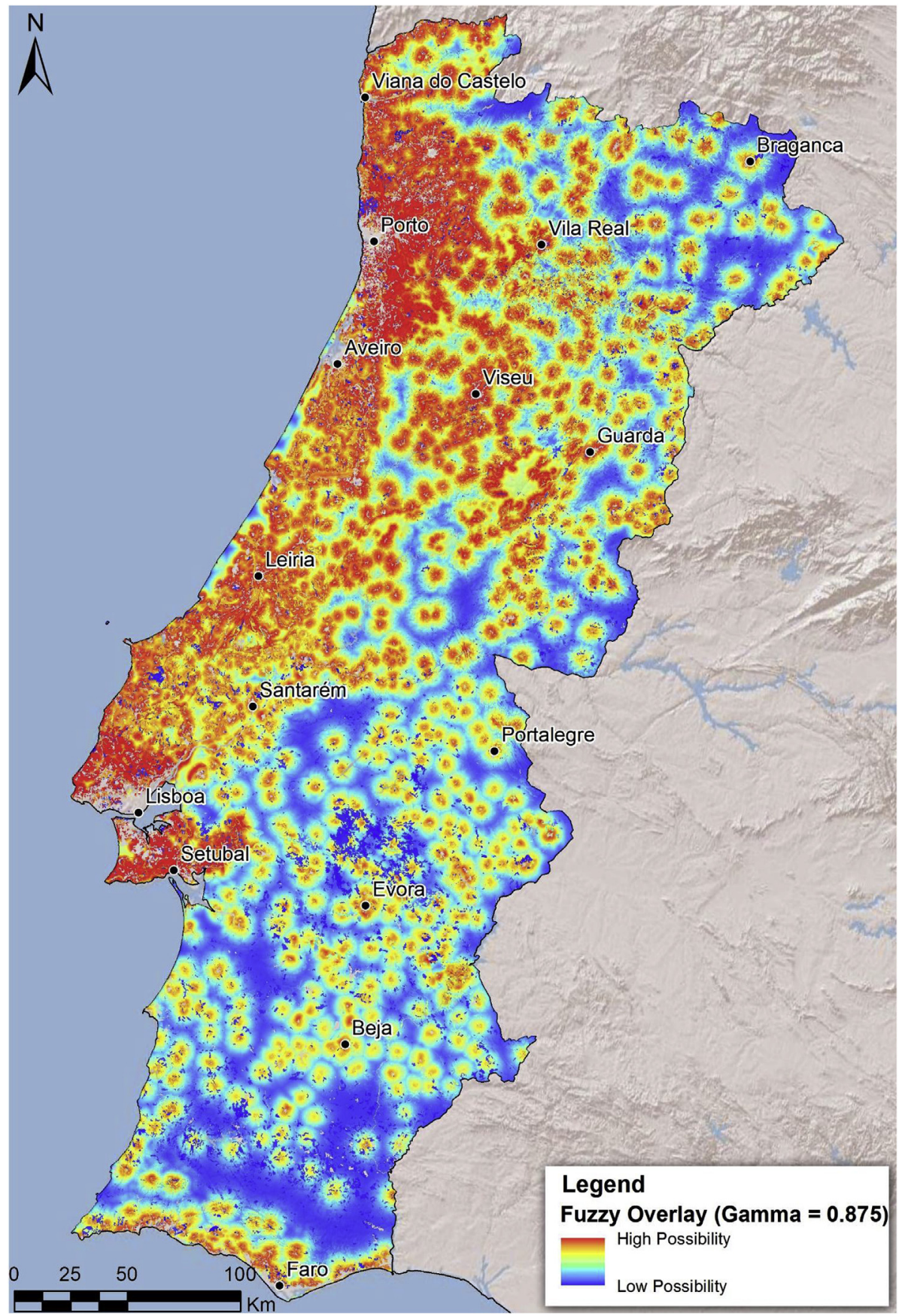

Fig. 7. Possibility RUI map for the year 2030 obtained from the fuzzy overlay using the best fitting parameters measured in the calibration phase.

error in locating the change measured by this parameter is partly due to a misclassification in the CLC map of 1990 for classes broadleaved and agro-forestry area, corrected only in the 2000 CLC map through the standard CLC procedure. Although this error affected the correct classification in this simulation, these two classes have been reclassified in our scheme as heterogeneous agricultural area and forest and semi-natural area respectively, and both contribute to our definition of the RUI. Moreover, the 2030 simulation map was not been affected by this error, as the MLP was trained on the 2000 and 2012 CLC map, which were not reporting these misclassifications.

\subsection{Fuzzification, possibilities and sensitivity analysis}

The transition potential map obtained from the MLP could also be interpreted as a susceptibility map. Hence, a transition potential map can be seen as a map expressing in a range from 0 to 100 the probability for a pixel of having the right conditions to experience a land use change. Therefore, a hypothetical overlay of the transition potential maps expressing the probability of having shifts toward urban fabric, heterogeneous agricultural areas and forest and seminatural areas could describe the tendency to generate the ruralurban interface. However, when mixing together these maps, each single pixel is considered as a target for different kinds of 

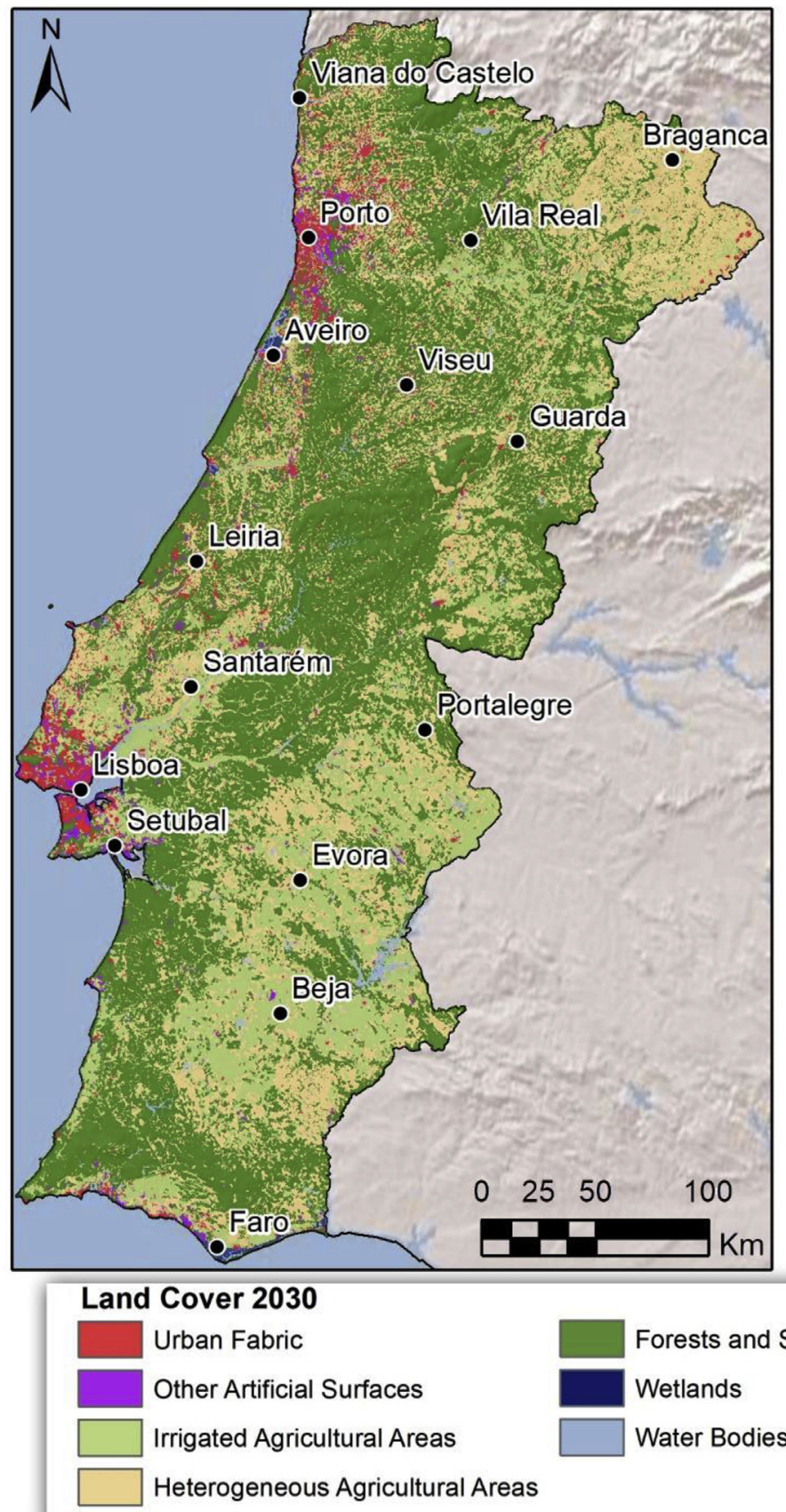

Urban Fabric

Other Artificial Surfaces

Irrigated Agricultural Areas

Heterogeneous Agricultural Areas

Wetlands

Water Bodies
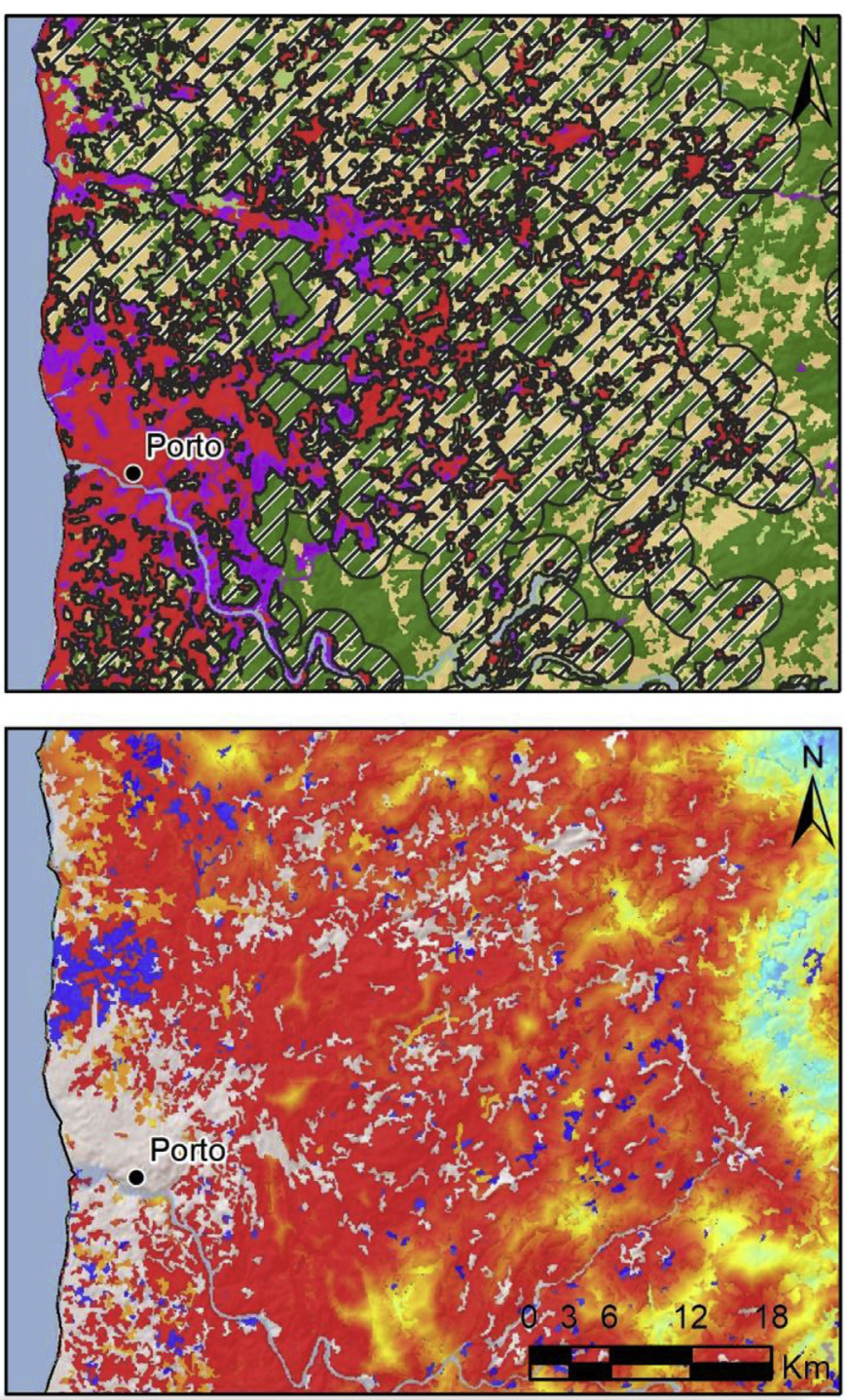

Rural-Urban Interface

Forests and Semi-natural Areas

Fuzzy Overlay (Gamma $\mathbf{= 0 . 8 7 5 )}$

High Possibility

Low Possibility

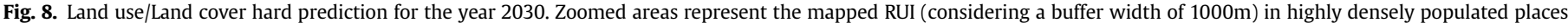
around Porto (a) and in scattered rural-residential areas in the South (b). 
possible transformations. Therefore, the use of fuzzy set theory was considered as a robust mathematical background to deal with this high level of uncertainty. To only consider the urban and the rural interaction, the transition probability maps of land cover changes toward heterogeneous agricultural areas and forests and seminatural areas were overlapped using a logical OR function (i.e. given two maps $A$ and $B$ the overlay is given by $\left((A+B)-\left(A^{*} B\right)\right)$ obtaining a transition probability of having changes toward rural.

A fuzzification of the transition potential map poses two issues. Firstly, the spread $f_{1}$ has to be defined for each fuzzification. Secondly, the ability of the fuzzy overlay to identify the areas most prone to be part of the RUI has to be validated.

To overcome these issues, a dataset of about 15,000 points was created. Points were chosen based on the RUI measured for the year 2012, in which hard boundaries were mapped as explained in section 2.2.1, ensuring a homogeneous distribution within the RUI and imposing a minimum distance among them of $1 \mathrm{~km}$. This dataset was then used to create 100 training/testing subsets, always having $70 \%$ of the points in the training set. They are considered as positive observations, i.e. points detecting the presence of the RUI. All the points were associated with the value of the corresponding pixel in both the maps of transition potential all-to-rural and all-to urban (Fig. 4). The mean values for each of the training sets for both urban and rural maps were then measured. These parameters were used as spread $f_{1}$ in creating 100 fuzzifications of the all-to-rural transition potential and 100 fuzzifications of the all-to-urban transition potential.

The fuzzy large membership function was used for the fuzzification of the all-to-urban map. In this way, the higher tendency of the pixel nearest to the urban area to influence the RUI has been considered. To the contrary, the use of the fuzzy near function in fuzzifying the all-to-rural map highlighted the higher propensity of the points in a distance between $500 \mathrm{~m}$ and $1 \mathrm{~km}$ from the rural coverages of influencing the shape of the RUI. The result of this process were 100 fuzzy maps expressing the possibility of the pixels of experiencing a transition toward rural coverages and being included in the RUI, and 100 fuzzy maps expressing the possibility of the pixels of being with a given distance from urban areas such as to be considered as part of the RUI. These maps were overlaid through three different JMF functions. This enabled an evaluation of the best JMF in describing RUI between the fuzzy Or, the fuzzy Sum and the fuzzy Gamma overlay rule.

To compare the overlay maps, randomly chosen pseudo-absence points were added to both the training and testing sets as negative observations, i.e. adding information about the absence of RUI. The resulting sets were used to verify the capability of the JMF maps of predicting the presence of the RUI. ROC and TOC curves were calculated for all the training and testing sets for all the fuzzy maps
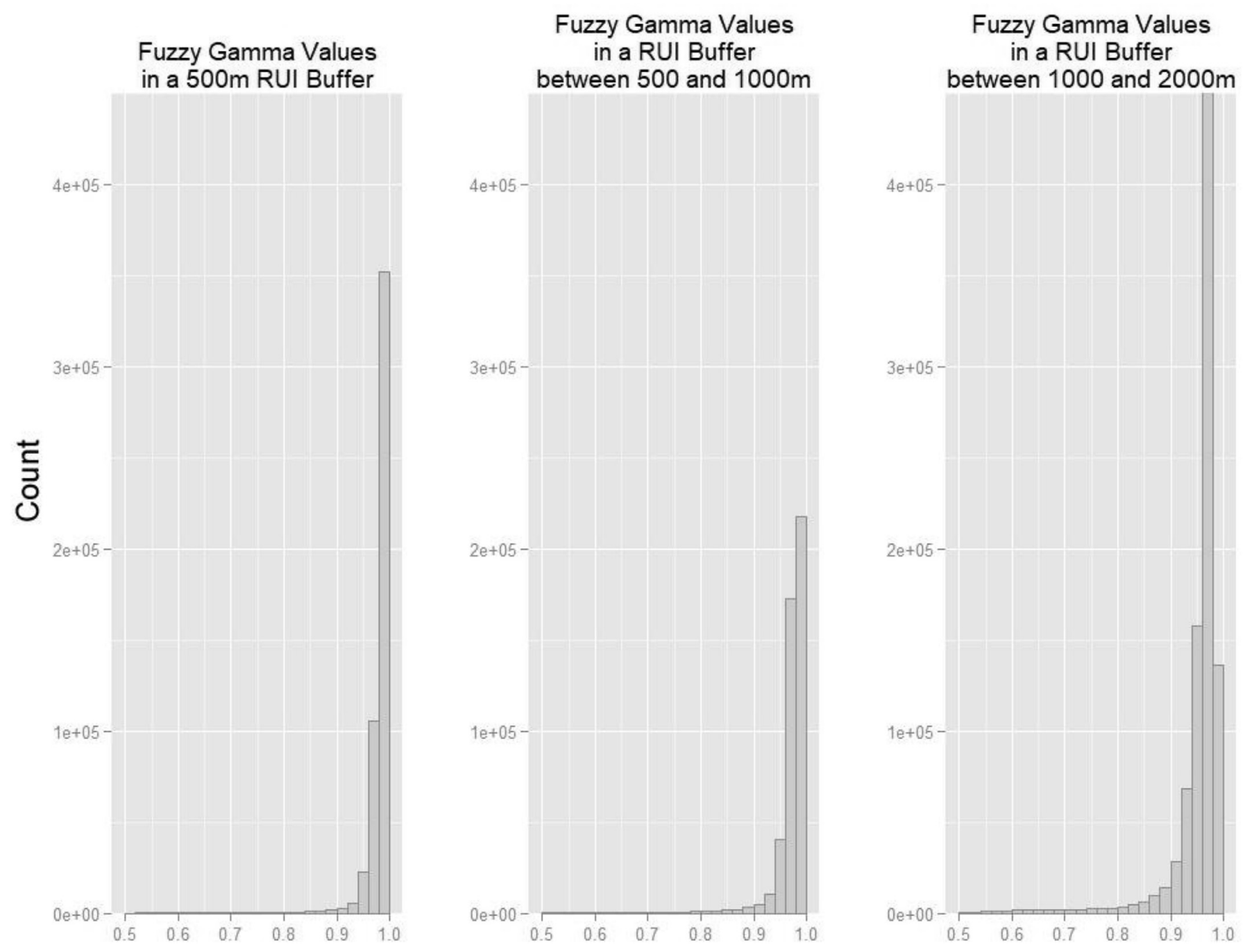

Fig. 9. Histograms of the Fuzzy Gamma Overlay functions for the year 2030 measured in the different buffer zones of the RUI. 
using the R package "TOC". Fig. 5 summarises the mean values of the AUC measured for all the maps.

The fuzzy gamma overlay function was found to be the best model in identifying the presence of RUI with a mean AUC value of 0.811 (and standard deviation of 0.003 ) for the training dataset and of 0.811 (and standard deviation of 0.002 ) with the testing dataset. Fig. 6 shows ROC and TOC curves for both training and testing sets measured for the best fitting combination of parameters in the fuzzification process and in the gamma overlay operation.

Specifically, the curves in Fig. 6 were obtained by using a spread of 0.6215 in the fuzzification of the all-to-urban potential map and a value of 0.6618 in the fuzzification of the all-to-rural map. Therefore, these parameters were also used in the simulation stage before performing a fuzzy gamma overlay.

\subsection{Change prediction maps}

The parameters obtained through the calibration and verified in the validation stage have been used to simulate LULCC in Portugal for the year 2030. Transition potential maps for 2030 obtained applying MLP have been used to identify the RUI through the procedure proposed in this paper. Fig. 7 shows the predicted RUI for the year 2030 obtained through the Fuzzy Gamma Overlay. The visual inspection of this map reveals that the areas where the RUI has the highest possibility to extend in 2030 are found around the most populated cities, driven by the growing peri-urban fringes of urban areas. Specifically, they are located in the area enclosed by Braga-Porto-Aveiro-Vila Real (in the northwestern area) with a spatial contiguity along the coast up to the city of Lisbon and the peninsula of Setubal, and crossing the city of Coimbra. Another highly predisposed area in the onrthern part of the country is located around the city of Viseu, in the Centro Region, while in the southern part clusters are visible along the coastline in the Faro Region, this last probably due to the expansion of tourism-led development. In the e northeastern mountainous region towards the interior and in the sothern part of the country, characterized by rolling plains, hotspots for RUI are scattered in the area, probably driven by the abandonment of agricultural activities and the consequent spreading of the forest.

To validate this fuzzy RUI map, the hard prediction for LULC 2030 was considered (Fig. 8). Following the standard procedure to map the RUI (Tonini et al., 2017a), which considers the intersection between the enhanced surface surrounding urban areas and the overlapping burnable vegetated rural areas, three different buffer widths of 500, 1000 and $2000 \mathrm{~m}$ were applied. An overlay between the different buffers and the fuzzy possibility RUI map allowed an evaluation of the capability of the latter to identify as most fireprone areas all those pixels included in the buffers.

Fig. 9 shows the histograms corresponding to the values of the pixels included in the different buffer widths. Noticeably, even in the buffer range between 1000 and $2000 \mathrm{~m}, 88.84 \%$ of the pixels have a possibility value higher than 90 , while $72.10 \%$ have a value higher than 95 . These values corresponded respectively to $92.11 \%$ and $85.96 \%$ for the buffer distance between 500 and $1000 \mathrm{~m}$ and to $93.29 \%$ and $90.54 \%$ for the buffer distance between 0 and $500 \mathrm{~m}$.

\section{Discussion}

Several studies highlighted how land use changes are among the primary fire ignition causes (Ganteaume et al., 2013). The rapid urbanization of the European Mediterranean countries over the last decades, principally due to the development of tourism and the huge growth of metropolitan areas, implicates a higher range of possible fire causes due to the presence of human-rural interactions (Hill et al., 2008; Lasaponara et al., 2006). Specifically, human activities influence the spatio-temporal characterisation of forest fires occurrence (Bar Massada et al., 2009). RUI evolves under the pressure of anthropogenic and environmental factors, such as urban growth and fragmentation, abandonment of rural areas, deforestation, and its mapping is closely related to LULCC. RUI has been deeply investigated by researchers and fire managers in the last decades, and several geospatial models for defining and mapping its extension have been developed. RUI mapping is indeed a fundamental tool for decision-makers in order to design their policies with regard to forest fires protection and prevention. In the present research, authors propose an innovative approach to assess the spatio-temporal variability of RUI, related to LULCC, with the final goal of elaborating a future scenario of this interface for Portugal. On the one hand, the proposed fuzzy RUI map can be modelled for different temporal horizons and different socioeconomic scenarios, so to consider the dynamic nature of land use over time. On the other hand, compared with the classical approaches used in RUI mapping, the information given by the fuzzy RUI map are richer and account for uncertainty. Hence, depending on the sensibility of decision-makers and on the available resources, different thresholds or defuzzification procedures can be applied to the map to identify the areas to be considered as RUI and in which implementing concrete and effective policies to reduce the exposure of the artificial surfaces to fire risks.

Concerning the methodology discussed in this paper, results shown in previous sections highlight the effectiveness of the proposed framework in identifying the RUI through a flexible approach. The main aim of the study was avoiding the rigid definition of boundaries rising from the classical binary classification methods. In this sense, fuzzy set theory offers a solid mathematical background on which solve the issue of labelling each pixel as belonging or not to the RUI through the assignation to each pixel of a degree of possibility of belonging to the RUI set.

Nevertheless, fuzzy set theory is not the only possible approach to deal with uncertainty. Recent studies have tested the effectiveness of multi-label classification in LULCC simulations (Omrani et al., 2015). Conventionally, LULCC simulation maps, such as the 2030 land cover map proposed in this paper, are the result of a mono-label classification where a single specific class is assigned to each pixel. However, to take into account the uncertainty deriving from a long-term prediction, multi-label approaches can be used to associate spatial unit with a set of multiple classes. Multi-label classifications have substantial differences with the fuzzy set theory (Boutell et al., 2004). Fuzzy membership functions are generally used to deal with ambiguity in the classification of an object, but their overall purpose is its precise classification (Malczewski, 2006). This is usually obtained through a defuzzification procedure, which derives a crisp set from a fuzzy one (Power et al., 2001). Differently, multi-label classifications are used to assign multiple classes to each object, and are based on the assumption that the different labels are not mutually exclusive (Omrani et al., 2017). Hence, multi-label classifications would not be effective in defining RUI, as a pixel can either be considered as belonging to the interface or not, and the two options are mutually exclusive.

\section{Conclusions}

The present paper introduces a new approach for elaborating a fuzzy map of the Rural Urban Interface, expressing the possibility of a pixel of belonging to the RUI set. The procedure, allowing to make a prediction, is based on Land Use/Land Cover simulation models. The study area includes the entire mainland Portugal, one of the most fire prone country in Europe.

A future scenario for LULCC was computed for the year 2030, based on the Corine Land Cover (CLC) maps representing observed 
land cover for the years 1990, 2000 and 2012. In this study, we adopted a spatially explicit inductive method, allowing to estimate the change transition potential between CLC1990 and CLC2000. Therefore, statistical functions and algorithms accounting for explanatory spatial variables (e.g. road network, population density, agricultural census, altitude, slope, etc.), based in our case on artificial neural network, and specifically Multilayer Perceptron (MLP) algorithm, were used for the transition potential modelling. Then, a Markov Chain procedure was applied to allocate the transition among different land covers in the period 2000-2012. A backpropagation algorithm was used to correctly train the MLP model. After the validation of the model, performed via Kappa statistics by comparing the simulated and the observed land cover maps for the year 2012, the transition potential was allocated from the CLC2012 to obtain the future land cover map for the year 2030. Despite its complexity, this procedure is extremely robust, especially considering how the application of a non-linear model is perfectly appropriate $\mathrm{f}$ to investigate phenomenon like land use/ land cover changes which are naturally non-linear. Moreover, it does not rely on expert knowledge inputs and provides a high goodness of fit value.

Once the LULCC scenario for the year 2030 has been created and validated, it was used to evaluate the possibility of each pixel to belong to the RUI set, by applying a fuzzification procedure. The fuzzy membership function was used for the fuzzification of the allclasses-to-urban and all-classes-to-rural map. The results of this process are fuzzy maps expressing at once the possibility of each pixel of experiencing a transition toward rural coverages and of being in a distance from urban areas. These maps were then overlapped through joint membership fuzzy functions, which overlays probability map of having shifts for the year 2030 toward the urban and the vegetated burnable rural areas. The resulting map well describe a future scenario of RUI in Portugal.

Actually in this country it does not exist jet a specific legislation about RUI (or WUI), but only one general mention at this regard in the National Plan to Protect the Forests against Wildfires, in the Portuguese Law 16/2009. In this Plan it is suggested the need of maintaining an external buffer strips around population clusters, especially in those with the highest fire vulnerability, in order to protect urban-forest interface. The fuzzy RUI map resulting from the present study represents in this context a key tool for policy makers. Indeed, it expresses with a different degree of certitude the possibility of an area to belong to the RUI, allowing to take actions where these possibility is higher. More in general, RUI maps represent a fundamental tool to give practical indications in term of land and fire management. For local interventions, and for land use policy purposes, it is necessary to define spatial limits. Moreover, when planning for future strategies, it is crucial to develop models for land change prediction. The method developed in this paper can be generalised to the investigation of the spatio-temporal evolution of urban-interface vulnerable areas different that the RUI: in all these cases, a map representing the tendency towards relevant land cover/use classes identified on a prospective map provides a much more realistic, useful and unbiased result than crisp maps.

\section{Software availability}

Name of the software Land Change Modeler for ArcGIS Software

Version $\quad 2.0$

Developers Clark Labs, Clark University

System requirements Microsoft Windows 7 or above, ESRI ${ }^{\circledR} \operatorname{ArcGIS}^{\circledR}$ 12.2 or later

Program size $500 \mathrm{MB}$
Contact address Clark Labs, Clark University, 950 Main Street Worcester, MA, 01610-1477 USA

Telephone +1.508 .793 .7526$

Fax $\quad+1.508 .793 .8842$

Web www.clarklabs.org

Name of the software TOC

Version $\quad 0.0-4$

Developers Robert G. Pontius, Alí Santacruz, Amin Tayyebi, Benoit Parmentier, Kangping Si

Maintainers Alì Santacruz

System requirements $\mathrm{R} 2.14 .0$ or later

Contact email amasantac@unal.edu.co

License GPL-2|GPL-3

Web https://CRAN.R-project.org/package $=$ TOC

\section{References}

Alados, C.L., Pueyo, Y., Barrantes, O., Escós, J., Giner, L., Robles, A.B., 2004. Variations in landscape patterns and vegetation cover between 1957 and 1994 in a semiarid Mediterranean ecosystem. Landsc. Ecol. 19, 545-561. https://doi.org/ 10.1023/B:LAND.0000036149.96664.9a.

Amato, F., Maimone, B.A., Martellozzo, F., Nolè, G., Murgante, B., 2016. The effects of urban policies on the development of urban areas. Sustainability 8 (297). https://doi.org/10.3390/su8040297.

Amato, F., Martellozzo, F., Nolè, G., Murgante, B., 2017. Preserving cultural heritage by supporting landscape planning with quantitative predictions of soil consumption. J. Cult. Herit. 23, 44-54. https://doi.org/10.1016/j.culher.2015.12.009.

Amato, F., Pontrandolfi, P., Murgante, B., 2015. Supporting planning activities with the assessment and the prediction of urban sprawl using spatio-temporal analysis. Ecol. Inf. 30, 365-378. https://doi.org/10.1016/j.ecoinf.2015.07.004.

An, P., Moon, W., Rencz, A., 1991. Application of fuzzy set theory for integration of geological, geophysical and remote sensing data. Can. J. Explor. Geophys. 27, $1-11$.

Antrop, M., 2004. Landscape change and the urbanization process in Europe. Landsc. Urban Plann. 67, 9-26. Development of European Landscapes. https:// doi.org/10.1016/S0169-2046(03)00026-4.

Antrop, M., 2000. Changing patterns in the urbanized countryside of Western Europe. Landsc. Ecol. 15, 257-270. https://doi.org/10.1023/A:1008151109252.

Asadi, P., Hosseini, S.M., Ataie-Ashtiani, B., Simmons, C.T., 2017. Fuzzy vulnerability mapping of urban groundwater systems to nitrate contamination. Environ. Model. Software 96, 146-157. https://doi.org/10.1016/j.envsoft.2017.06.043.

Badia-Perpinyá, A., Pallares-Barbera, M., 2006. Spatial distribution of ignitions in Mediterranean periurban and rural areas: the case of Catalonia. Int. J. Wildland Fire 15 (187). https://doi.org/10.1071/WF04008.

Bai, Y., Wang, D., 2006. Fundamentals of Fuzzy Logic Control - Fuzzy Sets, Fuzzy Rules and Defuzzifications, in: Advanced Fuzzy Logic Technologies in Industrial Applications. Springer London, London, pp. 17-36. https://doi.org/10.1007/9781-84628-469-4_2.

Bar-Massada, A., Stewart, S.I., Hammer, R.B., Mockrin, M.H., Radeloff, V.C., 2013. Using structure locations as a basis for mapping the wildland urban interface. J. Environ. Manag. 128, 540-547. https://doi.org/10.1016/j.jenvman.2013.06.021.

Bar Massada, A., Radeloff, V.C., Stewart, S.I., Hawbaker, T.J., 2009. Wildfire risk in the wildland-urban interface: a simulation study in northwestern Wisconsin. For Ecol. Manage 258, 1990-1999. https://doi.org/10.1016/J.FORECO.2009.07.051.

Batty, M., 1997. Cellular automata and urban form: a primer. Appl. Phys. A J. 63 (2), 266-274.

Bonham-Carter, G.F., Bonham-Carter, G.F., 1994. CHAPTER 9 - tools for map analysis: multiple maps. In: Geographic Information Systems for Geoscientists, pp. 267-337. https://doi.org/10.1016/B978-0-08-041867-4.50014-X.

Boutell, M.R., Luo, J., Shen, X., Brown, C.M., 2004. Learning multi-label scene classification. Pattern Recogn. 37, 1757-1771. https://doi.org/10.1016/j.patcog.2004. 03.009 .

Buckley, J.J., 2004. Uncertain probabilities III: the continuous case. Soft comput. - a fusion found. Methodol. Appl. 8, 200-206. https://doi.org/10.1007/s00500003-0263-5.

Burrough, P.A., 1989. Fuzzy mathematical methods for soil survey and land evaluation. J. Soil Sci. 40, 477-492. https://doi.org/10.1111/j.1365-2389.1989.tb01290. $\mathrm{x}$.

Bouillon, C., Fernandez Ramiro, M.M., Sirca, C., Fierro Garcia, B., Long Fournel, M., et al., 2012. European software tools for mapping wildland urban interfaces in the mediterranean context. In: Modelling Fire Behaviour and Risk. Universita di Sassari DIPNET, pp. 243-248, 978.-88-904409-7-7.

Catry, F.X., Rego, F.C., Bação, F.L., Moreira, F., 2009. Modeling and mapping wildfire ignition risk in Portugal. Int. J. Wildland Fire 18 (921). https://doi.org/10.1071/ WF07123.

Conedera, M., Tonini, M., Oleggini, L., Vega Orozco, C., Leuenberger, M., Pezzatti, G.B., 2015. Geospatial approach for defining the wildland-urban interface in the alpine environment. Comput. Environ. Urban Syst. 52, 10-20. https://doi.org/10.1016/j.compenvurbsys.2015.02.003.

Copernicus Programme, n.d. CORINE Land Cover - available at http://land. 
copernicus.eu/pan-european/corine-land-cover [WWW Document]. URL http:// land.copernicus.eu/pan-european/corine-land-cover.

Derksen, S., Keselman, H.J., 1992. Backward, forward and stepwise automated subset selection algorithms: frequency of obtaining authentic and noise variables. Br. J. Math. Stat. Psychol. 45, 265-282. https://doi.org/10.1111/j.20448317.1992.tb00992.x

d'Aquino, P., August, P., Balmann, A., Berger, T., Bousquet, F., Brondízio, E., Gotts, N.M., 2002. Agent-based models of land-use and land-cover change. In: Proc. of an International Workshop, pp. 4-7.

Di Palma, F., Amato, F., Nolè, G., Martellozzo, F., Murgante, B., 2016. A SMAP supervised classification of landsat images for urban sprawl evaluation. Isprs int. J. Geo-Information 5 (109). https://doi.org/10.3390/ijgi5070109.

Diogo, V., Koomen, E., 2012. Land-use change in Portugal, 1990-2006: main processes and underlying factors. Cartogr. Int. J. Geogr. Inf. Geovisualization 47, 237-249. https://doi.org/10.3138/carto.47.4.1504.

Eastman, J., Van Fossen, M.E., Solarzano, L.A., 2005. Transition potential modeling for land cover change. GIS. Spat. Anal. Model 357-386.

EEA, 1994. CORINE Land Cover - Part 1: Methodology.

EPIC WebGIS Portugal, n.d. EPIC WebGIS Portugal [WWW Document]. URL http:// epic-webgis-portugal.isa.ulisboa.pt/.

Eslami, E., Buckley, J.J., 2004. Uncertain probabilities II: the continuous case. Soft comput. - a fusion found. Methodol. Appl. 8, 193-199. https://doi.org/10.1007/ s00500-002-0262-y.

Foley, J.A., Ramankutty, N., Brauman, K.A., Cassidy, E.S., Gerber, J.S., Johnston, M., Mueller, N.D., O'connell, C., Ray, D.K., West, P.C., Balzer, C., Bennett, E.M., Carpenter, S.R., Hill, J., Monfreda, C., Polasky, S., Rockström, J., Sheehan, J., Siebert, S., Tilman, D., Zaks, D.P.M., 2011. Solutions for a cultivated planet. Nature 478, 337-342. https://doi.org/10.1038/nature10452.

Foley, J.A., Defries, R., Asner, G.P., Barford, C., Bonan, G., Carpenter, S.R., Chapin, F.S., Coe, M.T., Daily, G.C., Gibbs, H.K., Helkowski, J.H., Holloway, T., Howard, E.A. Kucharik, C.J., Monfreda, C., Patz, J.A., Prentice, I.C., Ramankutty, N., Snyder, P.K., 2005. Global consequences of land use. Science 309 (5734), 570-574. https:// doi.org/10.1126/science.1111772.

Ganteaume, A., Camia, A., Jappiot, M., San-Miguel-Ayanz, J., Long-Fournel, M. Lampin, C., 2013. A review of the main driving factors of forest fire ignition over Europe. Environ. Manag. 51, 651-662. https://doi.org/10.1007/s00267-0129961-z.

Gil Pontius Jr., R., Schneider, L.C., 2001. Land-cover change model validation by an ROC method for the Ipswich watershed, Massachusetts, USA. Agric. Ecosyst. Environ. 85, 239-248.

Guan, D., Gao, W., Watari, K., Fukahori, H., 2008. Land use change of Kitakyushu based on landscape ecology and Markov model. J. Geogr. Sci. 18, 455-468. https://doi.org/10.1007/s11442-008-0455-0.

Hanley, J.A., McNeil, B.J., 1982. The meaning and use of the area under a receiver operating characteristic (ROC) curve. Radiology 143, 29-36. https://doi.org/10. 1148/radiology.143.1.7063747.

Hattab, T., Ben Rais Lasram, F., Albouy, C., Sammari, C., Romdhane, M.S., Cury, P. Leprieur, F., Le Loc'h, F., 2013. The use of a predictive habitat model and a fuzzy logic approach for marine management and planning. PLoS One 8, e76430. https://doi.org/10.1371/journal.pone.0076430.

Haykin, S., 2008. Neural Networks and Learning Machines, third ed.

Herrero-Corral, G., Jappiot, M., Bouillon, C., Long-Fournel, M., 2012. Application of a geographical assessment method for the characterization of wildland-urban interfaces in the context of wildfire prevention: a case study in western Madrid. Appl. Geogr. 35, 60-70. https://doi.org/10.1016/j.apgeog.2012.05.005.

Hill, J., Stellmes, M., Udelhoven, T., Röder, A., Sommer, S., 2008. Mediterranean desertification and land degradation: mapping related land use change syndromes based on satellite observations. Global Planet. Change 64, 146-157. https://doi.org/10.1016/J.GLOPLACHA.2008.10.005.

Holland, J.H., Goldberg, D., 1989. Genetic Algorithms in Search, Optimization and Machine Learning. Addison-Wesley, Massachusetts.

Instituto Português do Mar e da Atmosfera [WWW Document], 2018. URL https:// www.ipma.pt/pt/index.html (accessed 3.16.18).

Kalnay, E., Cai, M., 2003. Impact of urbanization and land use change on climate. Nature 423, 528-531.

Kim, I., Arnhold, S., Ahn, S., Le, Q.B., Kim, S.J., Park, S.J., Koellner, T., 2017. Land use change and ecosystem services in mountainous watersheds: predicting the consequences of environmental policies with cellular automata and hydrological modeling. Environ. Model. Software. https://doi.org/10.1016/j.envsoft.2017. 06.018.

Kityuttachai, K., Tripathi, N., Tipdecho, T., Shrestha, R., 2013. Ca-markov analysis of constrained coastal urban growth modeling: hua hin seaside city, Thailand. Sustainability 5, 1480-1500. https://doi.org/10.3390/su5041480.

Lampin-Maillet, C., Jappiot, M., Long, M., Bouillon, C., Morge, D., Ferrier, J.-P., 2010. Mapping wildland-urban interfaces at large scales integrating housing density and vegetation aggregation for fire prevention in the South of France. J. Environ. Manag. 91, 732-741. https://doi.org/10.1016/j.jenvman.2009.10.001.

Lasaponara, R., Lanorte, A., Pignatti, S., Lasaponara, R., Lanorte, A., Pignatti, S., 2006. Characterization and mapping of fuel types for the mediterranean ecosystems of pollino national park in southern Italy by using hyperspectral MIVIS data. Earth Interact. 10, 1-11. https://doi.org/10.1175/EI165.1.

Li, X., Yeh, A.G.-O., 2002. Neural-network-based cellular automata for simulating multiple land use changes using GIS. Int. J. Geogr. Inf. Sci. 16, 323-343. https:// doi.org/10.1080/13658810210137004.

Li, X., Yeh, A.G.-O., 2001. Calibration of cellular automata by using neural networks for the simulation of complex urban systems. Environ. Plann. 33, 1445-1462. https://doi.org/10.1068/a33210.

Luo, X., Dimitrakopoulos, R., 2003. Data-driven fuzzy analysis in quantitative mineral resource assessment. Comput. Geosci. 29, 3-13.

Malczewski, J., 2006. Ordered weighted averaging with fuzzy quantifiers: GIS-based multicriteria evaluation for land-use suitability analysis. Int. J. Appl. Earth Obs. Geoinf. 8, 270-277. https://doi.org/10.1016/J.JAG.2006.01.003.

Martellozzo, F., Amato, F., Murgante, B., Clarke, K.C., 2018. Modelling the impact of urban growth on agriculture and natural land in Italy to 2030. Appl. Geogr. 91. https://doi.org/10.1016/j.apgeog.2017.12.004.

Mas, J.-F., Kolb, M., Paegelow, M., Camacho Olmedo, M.T., Houet, T., 2014. Inductive pattern-based land use/cover change models: a comparison of four software packages. Environ. Model. Softw. 51, 94-111. https://doi.org/10.1016/j.envsoft. 2013.09.010.

Meyfroidt, P., 2016. Approaches and terminology for causal analysis in land systems science. J. Land Use Sci. 11, 501-522. https://doi.org/10.1080/1747423X.2015. 1117530.

Millington, J.D.A., Perry, G.L.W., Romero-Calcerrada, R., 2007. Regression techniques for examining land use/cover change: a case study of a mediterranean landscape. Ecosystems 10, 562-578. https://doi.org/10.1007/s10021-007-9020-4.

Moreira, F., Rego, F.C., Ferreira, P.G., 2001. Temporal (1958-1995) pattern of change in a cultural landscape of northwestern Portugal: implications for fire occurrence. Landsc. Ecol. 16, 557-567. https://doi.org/10.1023/A:1013130528470.

Moreira, F., Vaz, P., Catry, F., Silva, J.S., 2009. Regional variations in wildfire susceptibility of land-cover types in Portugal: implications for landscape management to minimize fire hazard. Int. J. Wildland Fire 18 (563). https://doi.org/ 10.1071/WF07098.

Muñoz-Rojas, M., Jordán, A., Zavala, L.M., De la Rosa, D., Abd-Elmabod, S.K., AnayaRomero, M., 2015. Impact of land use and land cover changes on organic carbon stocks in mediterranean soils (1956-2007). Land Degrad. Dev. 26, 168-179. https://doi.org/10.1002/ldr.2194.

Murgante, B., Las Casas, G.B., 2004. G.I.S. and Fuzzy Sets for the Land Suitability Analysis. Springer, Berlin, Heidelberg, pp. 1036-1045. https://doi.org/10.1007/ 978-3-540-24709-8 109.

Nunes, A.N., Lourenço, L., Meira, A.C.C., 2016. Exploring spatial patterns and drivers of forest fires in Portugal (1980-2014). Sci. Total Environ. 573, 1190-1202. https://doi.org/10.1016/J.SCITOTENV.2016.03.121.

Nunes, M.C.S., Vasconcelos, M.J., Pereira, J.M.C., Dasgupta, N., Alldredge, R.J., Rego, F.C., 2005. Land cover type and fire in Portugal: do fires burn land cover selectively? Landsc. Ecol. 20, 661-673. https://doi.org/10.1007/s10980-0050070-8.

Nunes de Oliveira, S., Abílio de Carvalho Júnior, O., Trancoso Gomes, R.A., Fontes Guimarães, R., McManus, C.M., 2017. Deforestation analysis in protected areas and scenario simulation for structural corridors in the agricultural frontier of Western Bahia, Brazil. Land Use Pol. 61, 40-52. https://doi.org/10.1016/j. landusepol.2016.10.046.

Oliveira, S., Moreira, F., Boca, R., San-Miguel-Ayanz, J., Pereira, J.M.C., 2014. Assessment of fire selectivity in relation to land cover and topography: a comparison between Southern European countries. Int. J. Wildl. Fire 23 (620). https://doi org/10.1071/WF12053.

Oliveira, S., Zêzere, J.L., Queirós, M., Pereira, J.M., 2017. Assessing the social context of wildfire-affected areas. The case of mainland Portugal. Appl. Geogr 88 104-117. https://doi.org/10.1016/J.APGEOG.2017.09.004.

Omrani, H., Abdallah, F., Charif, O., Longford, N.T., 2015. Multi-label class assignment in land-use modelling. Int. J. Geogr. Inf. Sci. 29, 1023-1041. https://doi.org/10. 1080/13658816.2015.1008004

Omrani, H., Tayyebi, A., Pijanowski, B., 2017. Integrating the multi-label land-use concept and cellular automata with the artificial neural network-based Land Transformation Model: an integrated ML-CA-LTM modeling framework. GIScience Remote Sens. 54, 283-304. https://doi.org/10.1080/15481603.2016. 1265706.

OpenStreetMap [WWW Document], n.d. URL https://www.openstreetmap.org \#map=5/51.500/-0.100 (accessed 6.22.17)

Overmars, K.P., de Groot, W.T., Huigen, M.G.A., 2007a. Comparing inductive and deductive modeling of land use decisions: principles, a model and an illustration from the Philippines. Hum. Ecol. 35, 439-452. https://doi.org/10.1007 s10745-006-9101-6.

Overmars, K.P., Verburg, P.H., Veldkamp, T., 2007b. Comparison of a deductive and an inductive approach to specify land suitability in a spatially explicit land use model. Land Use Pol. 24, 584-599. https://doi.org/10.1016/j.landusepol.2005. 09.008.

Parker, D.C., Manson, S.M., Janssen, M.A., Hoffmann, M.J., Deadman, P., 2003. Multiagent systems for the simulation of land-use and land-cover change: a review. Ann. Assoc. Am. Geogr 93, 314-337. https://doi.org/10.1111/1467-8306. 9302004.

Pausas, J.G., Llovet, J., Rodrigo, A., Vallejo, R., 2008. Are wildfires a disaster in the Mediterranean basin? - A review. Int. J. Wildland Fire 17 (713). https://doi.org/ 10.1071/WF07151.

Pereira, M.G., Aranha, J., Amraoui, M., 2014. Land cover fire proneness in Europe For. Syst 23 (598). https://doi.org/10.5424/fs/2014233-06115.

Pereira, M.G., Teresa, J.C., DaCamara, C.C., Calheiros, T., 2013. Effects of regional climate change on rural fires in Portugal. Clim. Res. Clim Res 57, 187-200. https://doi.org/10.3354/cr01176.

Pereira, M.G., Trigo, R.M., da Camara, C.C., Pereira, J.M.C., Leite, S.M., 2005. Synoptic patterns associated with large summer forest fires in Portugal. Agric. For 
Meteorol 129, 11-25. https://doi.org/10.1016/j.agrformet.2004.12.007.

Platt, R., 2010. The wildland-urban interface: evaluating the definition effect. J. For 108 (1), 9-15.

Pontius, R.G., Boersma, W., Castella, J.C., Clarke, K., Nijs, T., Dietzel, C., Duan, Z. Fotsing, E., Goldstein, N., Kok, K., Koomen, E., Lippitt, C.D., McConnell, W., Moh Sood, A., Pijanowski, B., Pithadia, S., Sweeney, S., Trung, T.N., Veldkamp, A.T., Verburg, P.H., 2008. Comparing the input, output, and validation maps for several models of land change. Ann. Reg. Sci. 42, 11-37. https://doi.org/10.1007/ s00168-007-0138-2.

Pontius, R.G., Cheuk, M.L., 2006. A generalized cross-tabulation matrix to compare soft-classified maps at multiple resolutions. Int. J. Geogr. Inf. Sci. 20, 1-30. https://doi.org/10.1080/13658810500391024.

Pontius, R.G., Parmentier, B., 2014. Recommendations for using the relative operating characteristic (ROC). Landsc. Ecol. 29, 367-382. https://doi.org/10.1007/ s10980-013-9984-8.

Pontius, R.G.J., 2000. Quantification error versus location error in comparison of categorical maps. Photogramm. Eng. Rem. Sens. 66, 1011-1016.

Pontius Jr., R.G., Kangping, S., 2014. The total operating characteristic to measure diagnostic ability for multiple thresholds. Int. J. Geogr. Inf. Sci. 28, 570-583. https://doi.org/10.1080/13658816.2013.862623.

Portal do Instituto Nacional de Estatística, n.d. Portal do Instituto Nacional de Estatística [WWW Document]. URL https://www.ine.pt/xportal/xmain? xpgid=ine $\_$main\&xpid=INE.

Pota, M., Esposito, M., De Pietro, G., 2013. Transforming probability distributions into membership functions of fuzzy classes: a hypothesis test approach. Fuzzy Set Syst. 233, 52-73. https://doi.org/10.1016/j.fss.2013.03.013.

Power, C., Simms, A., White, R., 2001. Hierarchical fuzzy pattern matching for the regional comparison of land use maps. Int. J. Geogr. Inf. Sci. 15, 77-100. https:// doi.org/10.1080/136588100750058715.

Poyatos, R., Latron, J., Llorens, P., 2003. Land use and land cover change after agricultural abandonment: the case of a mediterranean mountain area (Catalan pre-pyrenees). Mt. Res. Dev. 23, 362-368. https://doi.org/10.1659/02764741(2003)023[0362:LUALCC]2.0.CO;2.

Radeloff, V.C., Hammer, R.B., Stewart, S.I., Fried, J.S., Holcomb, S.S., McKeefry, J.F. 2005. The wildland-urban interface in the United States. Ecol. Appl. 15, 799-805. https://doi.org/10.1890/04-1413.

Raines, G.L., Sawatzky, D.L., Bonham-Carter, G.F., 2010. Incorporating Expert Knowledge - New Fuzzy Logic Tools in ArcGIS 10.

Ramankutty, N., Coomes, O.T., 2016. Land-use regime shifts: an analytical framework and agenda for future land-use research. Ecol. Soc. 21 art1. https://doi.org 10.5751/ES-08370-210201.

Reference Data - Copernicus Land Monitoring Service [WWW Document], n.d. URL http://land.copernicus.eu/pan-european/satellite-derived-products/view (accessed 6.22.17).

Robin, X., Turck, N., Hainard, A., Tiberti, N., Lisacek, F., Sanchez, J.-C., Müller, M., 2011. pROC: an open-source package for $\mathrm{R}$ and $\mathrm{S}+$ to analyze and compare ROC curves. BMC Bioinf. 12 (77). https://doi.org/10.1186/1471-2105-12-77.

Robinson, D.T., Brown, D.G., Parker, D.C., Schreinemachers, P., Janssen, M.A Huigen, M., Wittmer, H., Gotts, N., Promburom, P., Irwin, E., Berger, T., Gatzweiler, F., Barnaud, C., 2007. Comparison of empirical methods for building agent-based models in land use science. J. Land Use Sci. 2, 31-55. https://doi. org/10.1080/17474230701201349.

Saeidi, S., Mohammadzadeh, M., Salmanmahiny, A., Mirkarimi, S.H., 2017. Performance evaluation of multiple methods for landscape aesthetic suitability mapping: a comparative study between Multi-Criteria Evaluation, Logistic Regression and Multi-Layer Perceptron neural network. Land Use Pol. 67, 1-12. https://doi.org/10.1016/j.landusepol.2017.05.014.

Sheehan, T., Gough, M., 2016. A platform-independent fuzzy logic modeling framework for environmental decision support. Ecol. Inf. 34, 92-101. https:/ doi.org/10.1016/j.ecoinf.2016.05.001.

Silva, R.F.B., da Batistella, M., Moran, E.F., 2016. Drivers of land change: humanenvironment interactions and the Atlantic forest transition in the Paraíba Valley, Brazil. Land Use Pol. 58, 133-144. https://doi.org/10.1016/j.landusepol.2016. 07.021

Stewart, S.I., Radeloff, V.C. Hammer, R.B., Hawbaker, T.J., 2007. Defining the wildland-urban interface. J. For. 105, 201-207.

Stewart, S.I., Wilmer, B., Hammer, R.B., Aplet, G.H., Hawbaker, T.J., Miller, C. Radeloff, V.C., 2009. Wildland-urban interface maps vary with purpose and context. J. For. 107, 78-83.

Takada, T., Miyamoto, A., Hasegawa, S.F., 2010. Derivation of a yearly transition probability matrix for land-use dynamics and its applications. Landsc. Ecol. 25 561-572. https://doi.org/10.1007/s10980-009-9433-X.

Theobald, D.M., Romme, W.H., 2007. Expansion of the US wildland-urban interface. Landsc. Urban Plann. 83, 340-354. https://doi.org/10.1016/j.landurbplan.2007. 06.002 .
Tonini, M., Parente, J., Pereira, M.G., 2017a. Global spatial assessment of WUI and related land cover in Portugal. Geophys. Res. Abstr. EGU Gen. Assem. Comput. Environ. Urban Syst 19, 2017-4956.

Tonini, M., Pereira, M.G., Parente, J., Vega Orozco, C., 2017b. Evolution of forest fires in Portugal: from spatio-temporal point events to smoothed density maps. Nat. Hazards 85, 1489-1510. https://doi.org/10.1007/s11069-016-2637-x.

Trigo, R.M., Sousa, P.M., Pereira, M.G., Rasilla, D., Gouveia, C.M., 2016. Modelling wildfire activity in Iberia with different atmospheric circulation weather types. Int. J. Climatol. 36, 2761-2778. https://doi.org/10.1002/joc.3749.

Viedma, O., 2008. The influence of topography and fire in controlling landscape composition and structure in Sierra de Gredos (Central Spain). Landsc. Ecol. 23, 657-672. https://doi.org/10.1007/s10980-008-9228-5.

USDI - US Department Of The Interior, USDA - US Department Of Agriculture, 2001. Urban wildland interface communities within the vicinity of federal lands that are at high risk from wildfire. Fed. Regist. 66, 751-777.

Uusitalo, L., Lehikoinen, A., Helle, I., Myrberg, K., 2015. An overview of methods to evaluate uncertainty of deterministic models in decision support. Environ. Model. Software 63, 24-31. https://doi.org/10.1016/j.envsoft.2014.09.017.

Van Doorn, A.M., Bakker, M.M., 2007. The destination of arable land in a marginal agricultural landscape in South Portugal: an exploration of land use change determinants. Landsc. Ecol. 22, 1073-1087. https://doi.org/10.1007/s10980007-9093-7.

van Vliet, J., Bregt, A.K, Brown, D.G, van Delden, $\mathrm{H}$, Heckbert, S., Verburg, P.H., 2016. A review of current calibration and validation practices in land-change modeling. Environ. Model. Software 82, 174-182. https://doi.org/10.1016/j. envsoft.2016.04.017.

Van Vliet, J., Bregt, A.K., Hagen-Zanker, A., 2011. Revisiting Kappa to account for change in the accuracy assessment of land-use change models. Ecol. Model. 222, 1367-1375. https://doi.org/10.1016/j.ecolmodel.2011.01.017.

van Vliet, N., Mertz, O., Heinimann, A., Langanke, T., Pascual, U., Schmook, B., Adams, C., Schmidt-Vogt, D., Messerli, P., Leisz, S., Castella, J.-C., Jørgensen, L., Birch-Thomsen, T., Hett, C., Bech-Bruun, T., Ickowitz, A., Vu, K.C., Yasuyuki, K., Fox, J., Padoch, C., Dressler, W., Ziegler, A.D., 2012. Trends, drivers and impacts of changes in swidden cultivation in tropical forest-agriculture frontiers: a global assessment. Global Environ. Change 22, 418-429. https://doi.org/10.1016/j. gloenvcha.2011.10.009.

Viedma, O., Moity, N., Moreno, J.M., 2015. Changes in landscape fire-hazard during the second half of the 20th century: agriculture abandonment and the changing role of driving factors. Agric. Ecosyst. Environ. 207, 126-140. https://doi.org/10. 1016/j.agee.2015.04.011.

Wang, L.-X., Mendel, J.M., 1992. Fuzzy basis functions, universal approximation, and orthogonal least-squares learning. IEEE Trans. Neural Network. 3, 807-814. https://doi.org/10.1109/72.159070.

Wieland, R., Mirschel, W., 2017. Combining expert knowledge with machine learning on the basis of fuzzy training. Ecol. Inf. 38, 26-30. https://doi.org/10. 1016/j.ecoinf.2017.01.001.

Yang, X., Zheng, X.-Q., Lv, L.-N., 2012. A spatiotemporal model of land use change based on ant colony optimization, Markov chain and cellular automata. Ecol. Model. 233, 11-19. https://doi.org/10.1016/j.ecolmodel.2012.03.011.

Young, S., 2017. Land change monitoring, assessment, and projection (LCMAP) revolutionizes land cover and land change research (No. 172). Gen. Inf. Prod. https://doi.org/10.3133/gip172.

Zadeh, L.A., 2008. Is there a need for fuzzy logic? Inf. Sci. 178, 2751-2779. https:// doi.org/10.1016/j.ins.2008.02.012.

Zadeh, L.A., 1999. Fuzzy logic and the calculi of fuzzy rules, fuzzy graphs, and fuzzy probabilities. Comput. Math. Appl. 37 (35). https://doi.org/10.1016/S08981221(99)00140-6.

Zadeh, L.A., 1973a. Outline of a new approach to the analysis of complex systems and decision processes. In: IEEE Trans. Syst. Man. Cybern. SMC-3, pp. 28-44. https://doi.org/10.1109/TSMC.1973.5408575.

Zadeh, L.A., 1973b. Outline of a new approach to the analysis of complex systems and decision processes. In: IEEE Trans. Syst. Man. Cybern. SMC-3, pp. 28-44. https://doi.org/10.1109/TSMC.1973.5408575.

Zadeh, L.A., 1965. Fuzzy sets. Inf. Control 8, 338-353. https://doi.org/10.1016/S00199958(65)90241-X

Zhang, Y., He, H.S., Yang, J., 2008. The wildland-urban interface dynamics in the southeastern U.S. from 1990 to 2000. Landsc. Urban Plann. 85, 155-162. https:// doi.org/10.1016/j.landurbplan.2007.11.007.

Zimmermann, H.-J., 2010a. Fuzzy set theory. Wiley Interdiscip Rev. Comput. Stat 2 317-332. https://doi.org/10.1002/wics.82.

Zimmermann, H.-J., 2010b. Fuzzy set theory. Wiley Interdiscip Rev. Comput. Stat 2, 317-332. https://doi.org/10.1002/wics.82.

Zimmermann, H.-J., 2001. Fuzzy Set Theory-and its Applications, fourth ed. Springer, Netherlands https://doi.org/10.1007/978-94-010-0646-0. 